\title{
VIVERE E MORIRE NEL CHIOSTRO: TEMI E PROSPETTIVE DI RICERCA
}

\section{GABRIELE ARCHETTI}

UDC: $27-78$

726.5

Original scientific paper

Manuscript received: 20. 04. 2017.

Revised manuscript accepted: 28. 04. 2017.

DOI: 10.1484/J.HAM.5.113702
G. Archetti

Dipartimento di storia moderna e contemporanea Università Cattolica del Sacro Cuore Largo Gemelli, 1, 20123 Milano, Italia gabriele.archetti@unicatt.it

The monastic life - explored through the eyes of monks and, so to speak, seen from the inside - is the perspective of the XXIII International Symposium dell'IRCLAMA. The meeting, through the study of the spaces and the time of the monastic observance, intends to penetrate deeply one of the fundamental structures of development of medieval society between East and West. The history, the art, the architecture and the archeology are the key tools whereby - through the words said and written by the protagonists, the places of prayer, the work and daily life, the images and the buildings (church, cloister, chapter, refectory, kitchen, library, scriptorium, dormitory, infirmary, garden, warehouses, guest house, etc.) untill the last home of the graves (common or elitist) in the cemetery - the forms of the small and great abbey complexes and their uses are examined, from the late antiquity to the magnificent cluniacense blooming, such as formative archetypes of the Christian medieval Europe.

Keywords: Monasticism, monastery, abbey, monks, cloister, Rule of Saint Benedict, ascetic life, monastic observance

Nell'Historia monachorum, scritta alla fine del V secolo e attribuita tradizionalmente a Rufino di Aquileia, si dice che il monastero di Isidoro nella Tebaide egiziana era «attorniato da spazi molto ampi e chiuso da un muro di cinta. Si trattava di un monastero per uomini che a loro disposizione avevano discrete abitazioni. Dentro il recinto vi erano parecchi pozzi d'acqua, giardini che potevano essere irrigati con poca fatica evi erano piante di ogni specie; l'avresti detto un paradiso terrestre. Vi si trovava tutto quanto era necessario per la vita, adatto ad ogni uso, e anche di più. Nessun monaco doveva avere delle ragioni per uscire fuori a cercare qualcosa che là mancasse, perché vi era di tutto»'. L'immagine mitizzata della clausura descrive il bisogno autarchico del ritiro di ogni esperienza monastica; nello stesso periodo Cirillo di Scitopoli (514 ca-557) conferma il medesimo principio a proposito della laura palestinese fondata nei pressi di Betlemme dall'abate Saba, ricordando che il padre

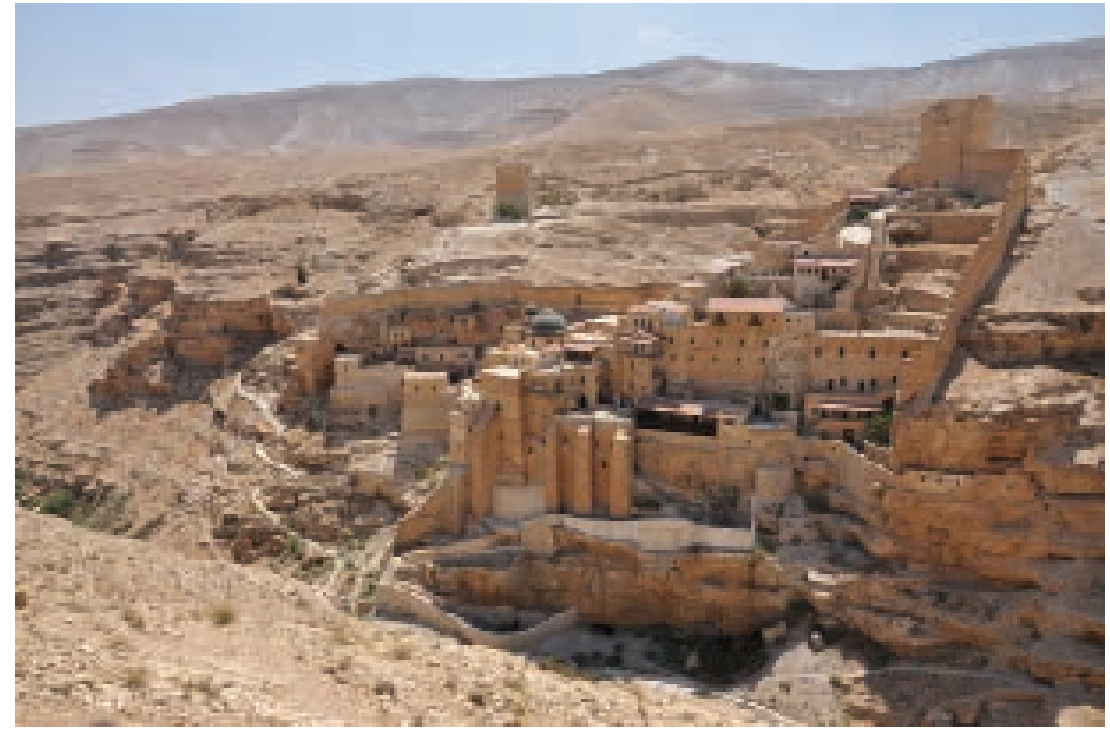

Fig. 1. Betlemme, monastero di Mar Saba vigilava «che i monaci avessero all'interno tutto il necessario, perché non fossero obbligati, a causa delle loro esigenze, ad uscire verso il mondo coloro che volevano ritirarsi dai tumulti del secolo» $»^{2}$ (fig. 1).

Se la scelta monastica è caratterizzata dalla rottura col mondo, il luogo del rifugio finale doveva avere l'essenziale

per vivere; in questo appare normale la convergenza tra gli anacoreti orientali e i criteri per l'edificazione di un monasterium indicati nella Regola benedettina: esso doveva «avere al proprio interno tutte le cose necessarie, cioè l'acqua, il mulino, l'orto e le strutture per le varie attività di lavoro, così che i monaci non dovessero uscire fuori, cosa che non gio-

\footnotetext{
* Sigle e abbreviazioni: HAM = Hortus artium medievalium; Ildemaro = R. MITTERMÜLLER, Expositio Regulae ab Hildemaro tradita, in Vita et Regula ss. p. Benedicti una cum expositione Regulae a Hildemaro tradita, Ratisbonae, Neo-Eboraci et Cincinnati 1880; La Règle de saint Benoît = La Règle de saint Benoît, Introduction, traduction et notes par A. de Vogüé, texte établi et présenté par J. Neufville, I-VI, Paris 1971-1972 (SC 181-186); MGH = Monumenta Germaniae historica; Precetti = Praecepta S. Pachomii, in Pachomiana latina, edd. A. Boon, L. Th. Lefort, Louvain 1932 (Bibliothèque de la Revue d'histoire ecclésiastique, 7); RB = Regula Benedicti; RM = Regula Magistri; Regolamenti = Oevres de S. Pachôme et de ses disciples, ed. L. Th. Lefort, Louvain 1959 (Corpus scriptorum christianorum orientalium, 159); SC = Sources chrétiennes.

${ }^{1}$ RUFINO, Historia monachorum, in Patrologia latina, 21, cap. 17, De monasterio abbatis Isidori, coll. 439-440; per una versione italiana si veda RUFINO DI CONCORDIA, Storia di monaci, Traduzione, introduzione e note a cura di G. Trettel, Roma 1991 (Collana di testi patristici, 91).

${ }^{2}$ Vita di Saba, cap. 18, in CIRILLO DI SCITOPOLI, Storie monastiche del deserto di Gerusalemme, Introduzione di L. Perrone, traduzione a cura di R. Baldelli e L. Mortari, note di L. Mortari, Abbazia di Praglia, Bresseo di Teolo (Pd) 1990 (Scritti monastici, 15), p. 231.
} 


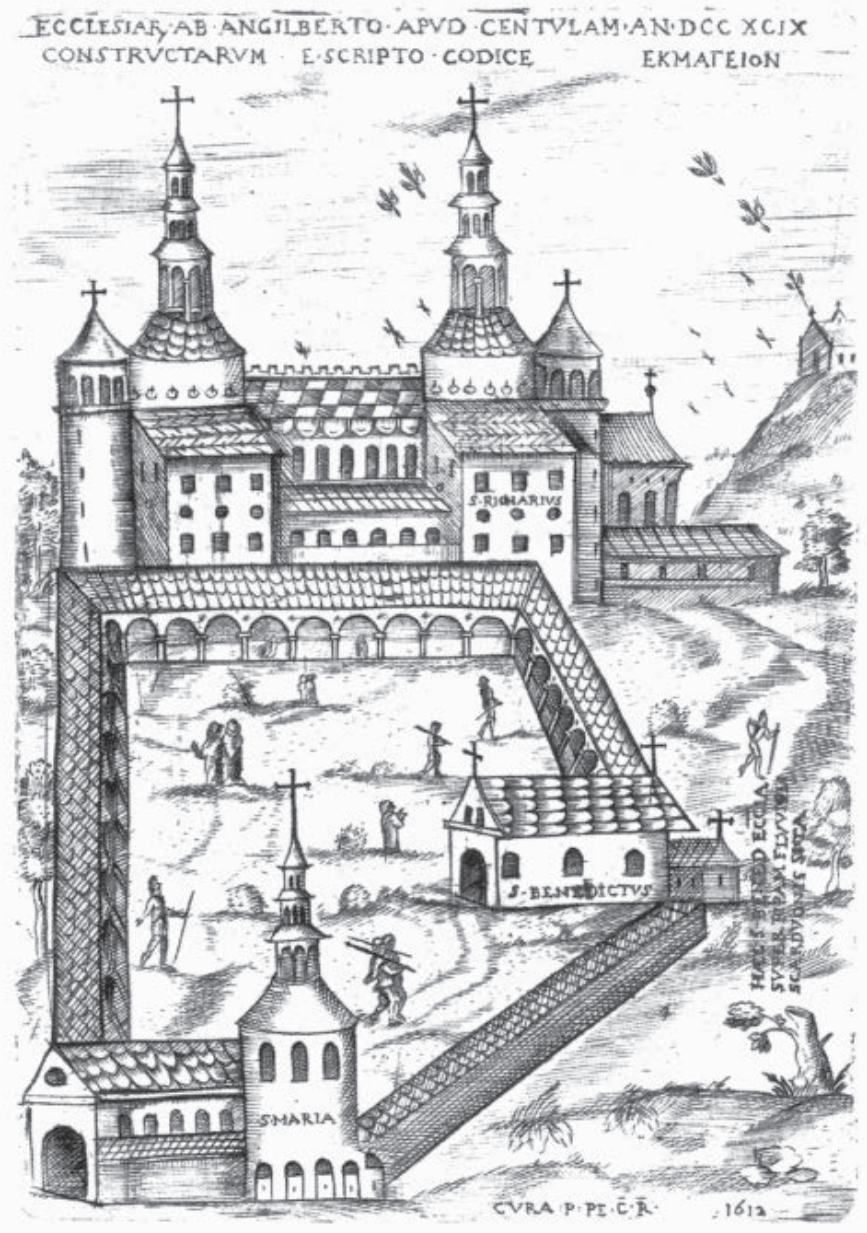

Fig. 2. Centula, Saint-Riquier, incisione del complesso abbaziale eseguita da Paul Petau, 1612

vava alle loro anime» (RB 66,6-7; RM 95,17). Ciò significa che al costruttore di un cenobio, come osserva a metà del secolo IX il commentatore benedettino Ildemaro di Corbie, spettava la «valutazione della congruità o dei pericoli esistenti nella scelta del posto», se ad esempio non vi fossero vincoli regi, comitali o vescovili, oppure impedimenti causati dalla contiguità di una curtis pubblica, quali la circolazione di persone estranee, di chierici, laici e donne ${ }^{3}$. La disponibilità di risorse naturali e la quiete dell'isolamento, inoltre, avrebbero consentito ai fratelli di evitare di lasciare il chiostro, trovandovi ciò di che vivere per sé e per i servi, come pure per l'accoglienza e la carità; mezzi che il fondatore avrebbe dovuto provvedere o garantire con i propri beni ${ }^{4}$ (fig. 2).
Per il monaco franco la vita monastica si svolgeva nel chiostro, cioè all'interno dello «spazio chiuso tra portico e portico» o della corte cintata che delimitava il luogo «dove stavano i monaci» ${ }^{5}$ (fig. 3). Tale spazio doveva essere delle giuste dimensioni, né troppo grande né troppo piccolo ma proporzionato al numero dei fratelli e al posto, per consentire l'esercizio delle loro attività e «la stabilitas della comunità, senza favorire alcuna occasione di distrazione esterna» ${ }^{6}$; evitando cioè che l'osservanza regolare, come nota Cirillo di Scitopoli nella Vita di Eutimio, potesse essere compromessa dal mutamento della residenza: «Un albero continuamente trapiantato non può fruttificare: allo stesso modo un monaco non porta frutto se passa da un posto all'altro. Se dunque si cercano i mezzi di operare bene nel luogo in cui si è, e non ci si riesce, non si creda che si possa riuscirvi altrove: ciò che è in questione non è il sito, ma le disposizioni della volontà» ${ }^{7}$.

Per questo motivo, continua ancora Ildemaro, secondo molti il chiostro deve misurare «cento piedi in ogni sua parte - circa 30 metri -, non di meno, altrimenti è troppo piccolo», e questa lunghezza era quella minima sotto cui non si doveva andare ${ }^{8}$. Illustrando il capitolo sugli «strumenti delle buone opere» ( $\mathrm{RB} 4$ ), aggiunge che il monastero viene definito con la parola officina, per indicare gli spazi dove tali instrumenta - preghiere, digiuni, meditazioni, obbedienza, ecc. - venivano diligentemente usati dai monaci; il cenobio di conseguenza era organizzato alla stregua di una fabrica e le domus in cui si articolava costituivano l'ambito in cui si effettuavano i vari lavori. Benedetto fa coincidere il claustrum col lo spazio delle officinae, "poiché in esso si compiono varie cose nei singoli luoghi, come appunto nei laboratori le diversae artes sono svolte da differenti magistri, vale a dire quando alcuni leggono, altri cantano, fanno qualcosa di manuale, lavorano in cucina e così via» ${ }^{9}$.

La centralità del chiostro nell'esperienza monastica è tale per le forme di vita cenobitica e per quelle eremitiche, come mostra Cirillo di Scitopoli a proposito della laura di San Saba, fuori della quale «si costrui, a settentrione, un cenobio affinché coloro che rinunciavano al mondo potessero ricevervi la formazione e la disciplina monastica e poi andare ad abitare alla laura $»^{10}$; e Pier Damiani a metà dell'XI secolo, presentando ai monaci di Fonte Avellana le norme seguite nell'eremo di Santa Croce, osserva: «Abbiamo costruito un claustrum di fianco alla chiesa, con quest'intenzione: se taluni si dilettano ancora della consuetudine che ha preso sviluppo nell'ordine monastico, abbiamo dove fare delle processioni solenni, secondo l'uso, nelle maggiori festività; al medesimo fine abbiamo procurato anche una croce d'argento assai adatta. Con la stessa intenzione, per venire

3 Ildemaro, pp. 606-607; e la ripresa in G. ARCHETTI, "Dilexi decorem domus tuae". Committenza aristocratica e popolare in ambito claustrale (secoli VIII-XII), in Il Medioevo: i committenti, Atti del Convegno internazionale di studi (Parma, 21-26 settembre 2010), a cura di A.C. Quintavalle, Milano 2011 (I convegni di Parma, 13), pp. 242-244; IDEM, Spazi e strutture claustrali nei commenti carolingi alla Regola benedettina, HAM, 20/2 (2014), pp. 450-451; qualche osservazione anche in IDEM, Boscose solitudini. Simboli, immagini e figure dal mondo monastico, in Medioevo: natura e figura. La raffigurazione dell'uomo e della natura nell'arte medievale, XIV Convegno internazionale di studi (Parma, 20-25 settembre 2011), a cura di A.C. Quintavalle, Milano 2015 (I convegni di Parma, 14), pp. 169-182.

${ }^{4}$ Ildemaro, pp. 606-607; ARCHETTI, “Dilexi decorem domus tuae”, pp. 243-244; IDEM, Spazi e strutture claustrali, p. 451.

${ }^{5}$ Ildemaro, p. 184.

${ }^{6}$ Ildemaro, pp. 182-184, 613.

7 Vita di Eutimio, cap. 19, in CIRILLO DI SCITOPOLI, Storie monastiche del deserto, p. 145.

${ }^{8}$ Ildemaro, pp. 183-184.

9 Ildemaro, p. 183, anche pp. 139, 182-183; ARCHETTI, "Dilexi decorem domus tuae", pp. 243-244; IDEM, Spazi e strutture claustrali, pp. $450-451$.

${ }^{10}$ Vita di Giovanni l'Esicasta, cap. 6, in CIRILLO DI SCITOPOLI, Storie monastiche del deserto di Gerusalemme, p. 330; Il cammino del monaco. La vita monastica secondo la tradizione dei padri, Introduzione, scelta e traduzione dalle lingue originali a cura di L. d'Ayala Valva, Prefazione di E. Bianchi, Magnano (Bi) 2009, p. 92. 


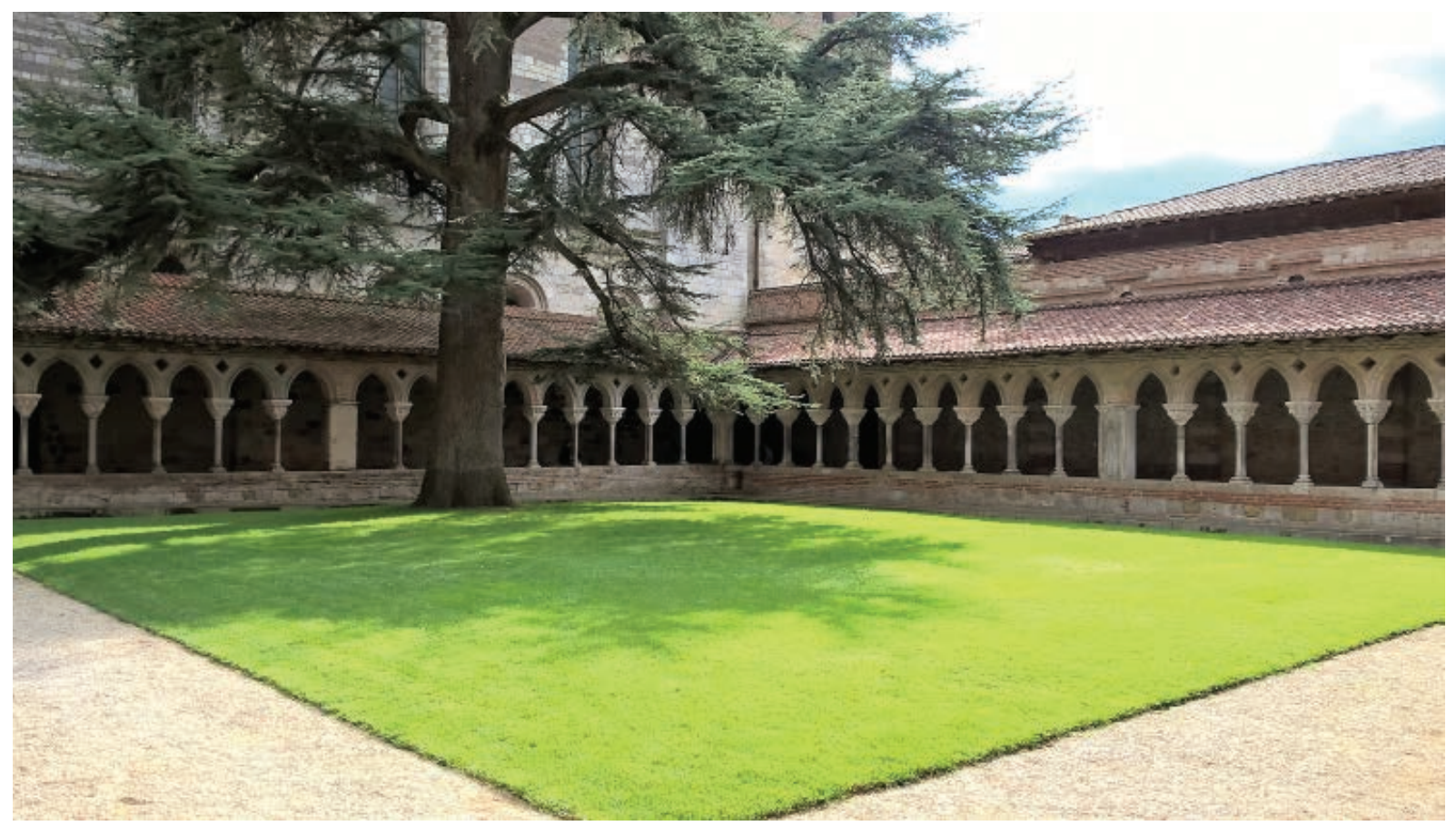

Fig. 3. Moissac, abbazia di San Pietro, chiostro, 1100

in aiuto della debolezza dei più fragili, abbiamo comprato anche dei campanelli, dei bacili e diversi altri strumenti per l'uso liturgico»"

\section{VIVERE E MORIRE NEL CHIOSTRO}

La vita monastica indagata con gli occhi dei monaci e, per così dire, vista dall'interno è la prospettiva del XXIII Simposio internazionale dell'IRCLAMA. Un appuntamento che, mediante lo studio degli spazi e dei tempi dell'osservanza claustrale, intende penetrare in profondità una delle strutture fondamentali dello sviluppo, tra Oriente e Occidente, della società medievale. Storia, arte, architettura e archeologia sono i principali strumenti con cui, attraverso le parole dette e scritte dai protagonisti, i luoghi della preghiera, del lavoro e della vita quotidiana, le immagini e le costruzioni (chiesa, chiostro, capitolo, refettorio, cucina, biblioteca, scriptorium, dormitorio, infermeria, orto, magazzini, foresteria, ecc.), fino all'ultima dimora delle sepolture, comuni o elitarie, nel cimitero si esaminano le forme di piccoli e grandi complessi abbaziali e i loro usi, dalla tarda antichità alla grandiosa fioritura cluniacense, quali archetipi formativi dell'Europa cristiana medievale (fig. 4).

Il tempo per Dio e lo spazio della preghiera, corale e personale, si modulano così attraverso il vissuto di eremiti ecenobiti - documentato dalle fonti scritte, dai resti materiali, dalle sopravvivenze edilizie, dalle pareti dipinte o scolpite delle chiese - lungo le stagioni della vita e le sue occupazioni. Ne risulta uno spaccato dai colori intensi che guarda alla realtà di un'esistenza aperta alle necessità interne dei chiostri, ma non indifferente allo scorrere delle vicende esterne, attenta nel gestire gli interessi materiali, sempre orientati da finalità spirituali, di patrimoni sovente assai consistenti. La strada verso la perfezione appare perciò mediata dal confronto fraterno, dal lavoro materiale e intellettuale, dal servizio di generosa accoglienza a poveri e pellegrini, dal nutrimento corporale unito alla ritualità di quello spirituale, dalle vie dell'azione educativa dei piccoli oblati e della carità verso i fratelli più deboli, sino ai gesti di pietà che con la morte spalancano ai fratelli le porte della vita celeste ${ }^{12}$.

Naturalmente la scelta dell'ascesi monastica, nelle sue declinazioni anacoretica e comunitaria, apre a mondi reali

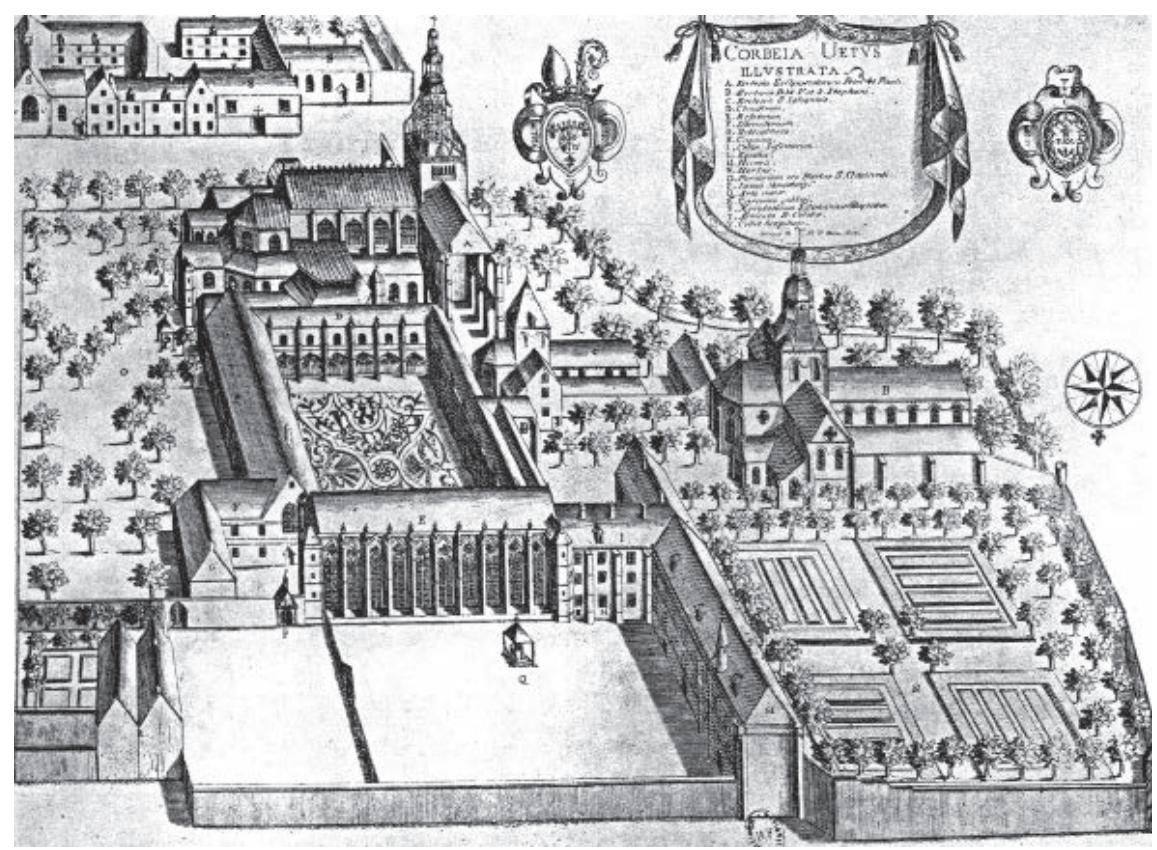

Fig. 4. Corbeia Vetus illustrata, veduta generale dell'abbazia di Corbie con la collocazione degli ambienti monastici, XVII secolo

"PIER DAMIANI, Lettere (1-21), a cura di G.I. Gargano e N. D’Acunto, traduzioni di A. Dindelli, L. Saraceno, C. Somigli, Roma 2000 (Opere di Pier Damiani, 1/1), epist. 18, cap. 20, pp. 339, 341.

${ }^{12}$ È questo il senso delle cinque sessioni che hanno segnato i lavori congressuali e caratterizzano il presente volume: I. Strutture di vita e spazi liturgici, con i saggi di Carmelina Urso, Fadia Abou Sekeh, Jorge López Quiroga, Cesare Alzati, Paul Tombeur, Laura de Castellet, Jordina Sales-Carbonell, Marta 


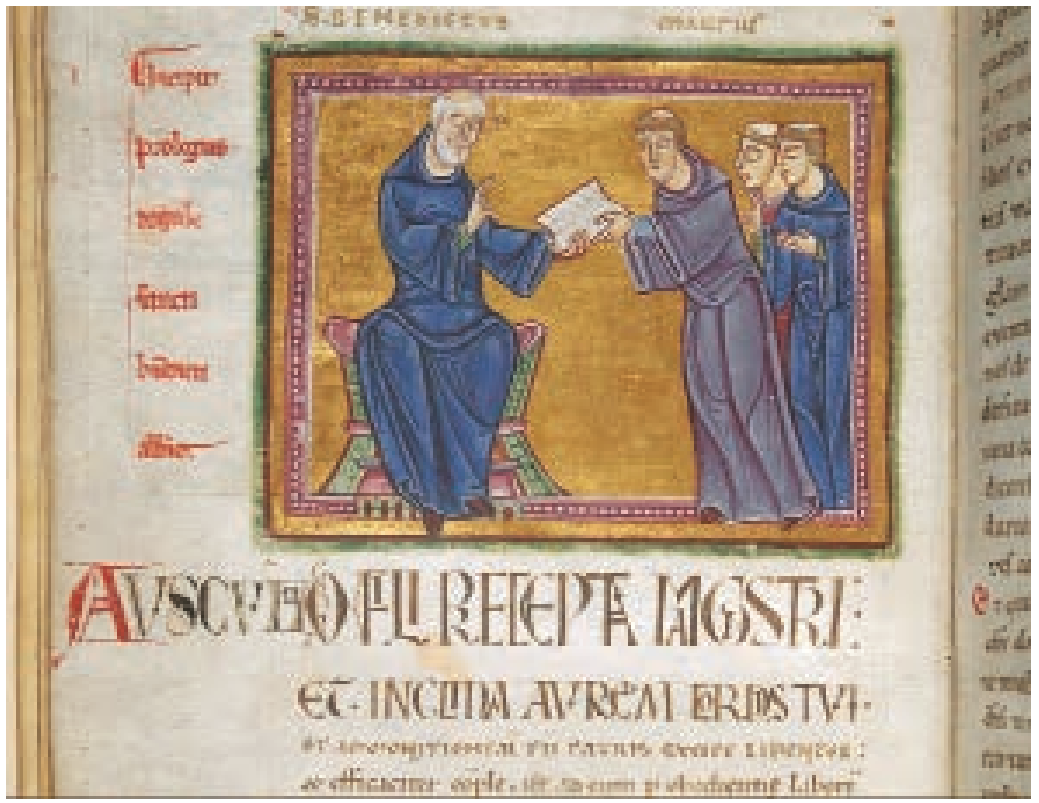

Fig. 5. London, British Library, ms Add 16979, f. 21v, Incipit della regola benedettina, con San Benedetto, Mauro e alcuni monaci, 1129

e a paesaggi dell'anima molto diversi tra loro e non sempre del tutto codificabili, offrendo una varietà di esperienze religiose che, da questo punto di vista, non sono riconducibili a modelli necessariamente unitari, né sarebbe giusto farlo. Ciòvale anche per le strutture materiali che, a lungo, hanno risposto più ai bisogni contingenti delle singole comunità che a schemi precostituiti. Certo, in questa unità degli intenti nella varietà delle forme molti sono i caratteri che appaiono comuni - l'obbedienza, l'umiltà, il silenzio, la preghiera, il canto, il lavoro, lo studio, la moderazione, l'astinenza, il digiuno, la carità, ecc. - ma si tratta di percorsi personali, misteriosi e quasi insondabili, come ricorda il Prologo della Regola: Obsculta, o fili, praecepta magistri et inclina aurem cordis tui (RB Prologo 1). Dimenticarsene non rende un buon servizio alla ricerca storica e impedisce di comprendere l'essenza profonda del monachesimo che va oltre le cose, le strutture e persino le singole scelte religiose (figg. 5, 6).

Spazio e tempo del vivere claustrale toccano una tematica assai ampia. Nel corso dei secoli, infatti, da Oriente a Occidente l'ascesi cristiana ha conosciuto forme di vita, esperienze e comunità molto diverse tra loro, non solo perché i vari monasteri seguivano regole e usi differenti, ma anche perché nel grande alveo della tradizione benedettina, dopo la riforma di Aquisgrana, le numerose famiglie riformate hanno reinterpretato, storicizzandolo in forme via via nuove e peculiari, il dettato della Regola. Basta esaminare i libri consuetudinum per averne un quadro variamente articolato, testi di solito molto attenti - trattandosi di fonti normative - a descrivere in modo ordinato le disposizioni riguardanti ogni ora del giorno e della notte; ciò che essi non rivelano però è l'osservanza reale all'interno dei cenobi, il vissuto di schiere di fratelli e di sorelle che nel silenzio dei

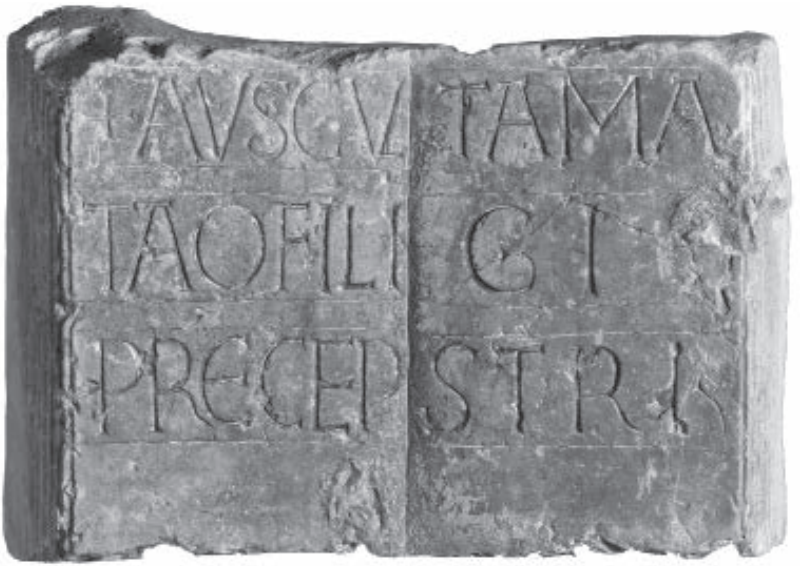

Fig. 6. Leno, proprietà Lanti, libro in pietra calcarea di Botticino con le parole iniziali della Regola benedettina, fine XII secolo

chiostri hanno speso la loro esistenza sui sentieri della perfezione cristiana. Un problema aperto agli sviluppi storici, dunque, e alla mutevolezza delle istituzioni, dove molto molto dipendeva dal superiore e dalla sua capacità di governo.

Le consuetudines tuttavia, se prese in se stesse, per la loro natura rischiano di comunicare un'impressione ingannevole di routine pacifica e indisturbata, che solo per brevi periodi può essere stata vera, mentre la prassi giornaliera risentiva delle contingenze dei tempi e dei luoghi che potevano incidere anche in modo profondo sulla regolarità disciplinare. Le vicende stesse delle abbazie che hanno avuto una storia plurisecolare, inoltre, mostrano che a periodi di stretta osservanza ne sono seguiti altri segnati da minore tensione spirituale, che la capacità di attrazione non è mai stata la stessa e la risposta data alle attese di rinnovamento ha incontrato un favore alterno. Non si deve trascurare poi che la prassi regolare, come nota Ildemaro, nei piccoli cenobi rurali (fig. 7) era molto diversa da quella nei grandi centri monastici, dove militavano decine o centinaia di fratelli, che un'abbazia urbana seguiva ritmi improponibili per le fondazioni abituate alla solitudine eremitica e gli usi dettati dal contesto locale o dalla collocazione geografica ${ }^{13}$.

Studi e ricerche sul monachesimo sono un tratto distintivo delle indagini medievistiche. Per qualche utile, quanto sommaria indicazione storiografica, nella ricchissima produzione bibliografica di ambito spirituale, storico-religioso e critico-documentario, basta scorrere gli indici delle riviste promosse dalle singole famiglie religiose - «Benedictina», «Revue bénédictine», «Revue Mabillon», «Cistercium», «Cahiers cisterciens», «Collectanea cistercensia», «Rivista cistercense», «Liens cisterciens», «Bulletin du Centre d'études Clunisiennes», «Liturgie», «La vie spirituelle», «L'Ulivo», «Ora et labora», «Studia monastica», «Cuadernos monásticos», «The American Benedictine Review», «The Journal of Medieval Monastic Studies», ecc. -, le collane di carattere tematico, quali "Miscellanea cassinese" e la "Biblioteca della

Sancho i Planas, Roberto Cassanelli, Francesca Stroppa, Massimo De Paoli, Fabrizio Bisconti e Carla Bino; II. Forme claustrali e simboli religiosi, con saggi di Roberta Cerone, Gerardo Boto Varela, Imma Lorés, Xavier Costa Badia, Artemio Manuel Martínez Tejera, Marcello Rotili, Maria Cristina Rossi, Margherita Tabanelli, Milagros Guardia, Ivan Josipović, Ivana Tomas e Gian Pietro Brogiolo; III. Costruire e lavorare nel mondo monastico, con saggi di Pietro Dalena, Fabio Redi, Paolo De Vingo, Alessandro Di Muro, Antonio Macchione, Nicolas Reveyron, Paola Galetti, Vasco La Salvia, Simona Gavinelli e Mattia Cosimo Chiriatti; IV. Acesi del cibo, assistenza e carità, con saggi di Antoni Riera i Melis, Roberto Bellini, Roberto Greci, Giuliana Albini, Mia Rizner, Maria Soler Sala, Alessia Frisetti, Nicola Busino, Thomas E. Schweigert e Gabriele Castiglia; V. Con lo sguardo oltre il tempo, con saggi di Daniel Lemeni, Giuseppe Motta, Simona Moretti, Jorge Rodrigues, Rutger Kramer, Veronika Wieser, Daniele Ferraiuolo, Meta Niederkorn, Paola Novara e Debora Ferreri.

${ }^{13}$ Ildemaro, pp. 309, 323-330 passim, 396, 479-48o, 503, 584. 


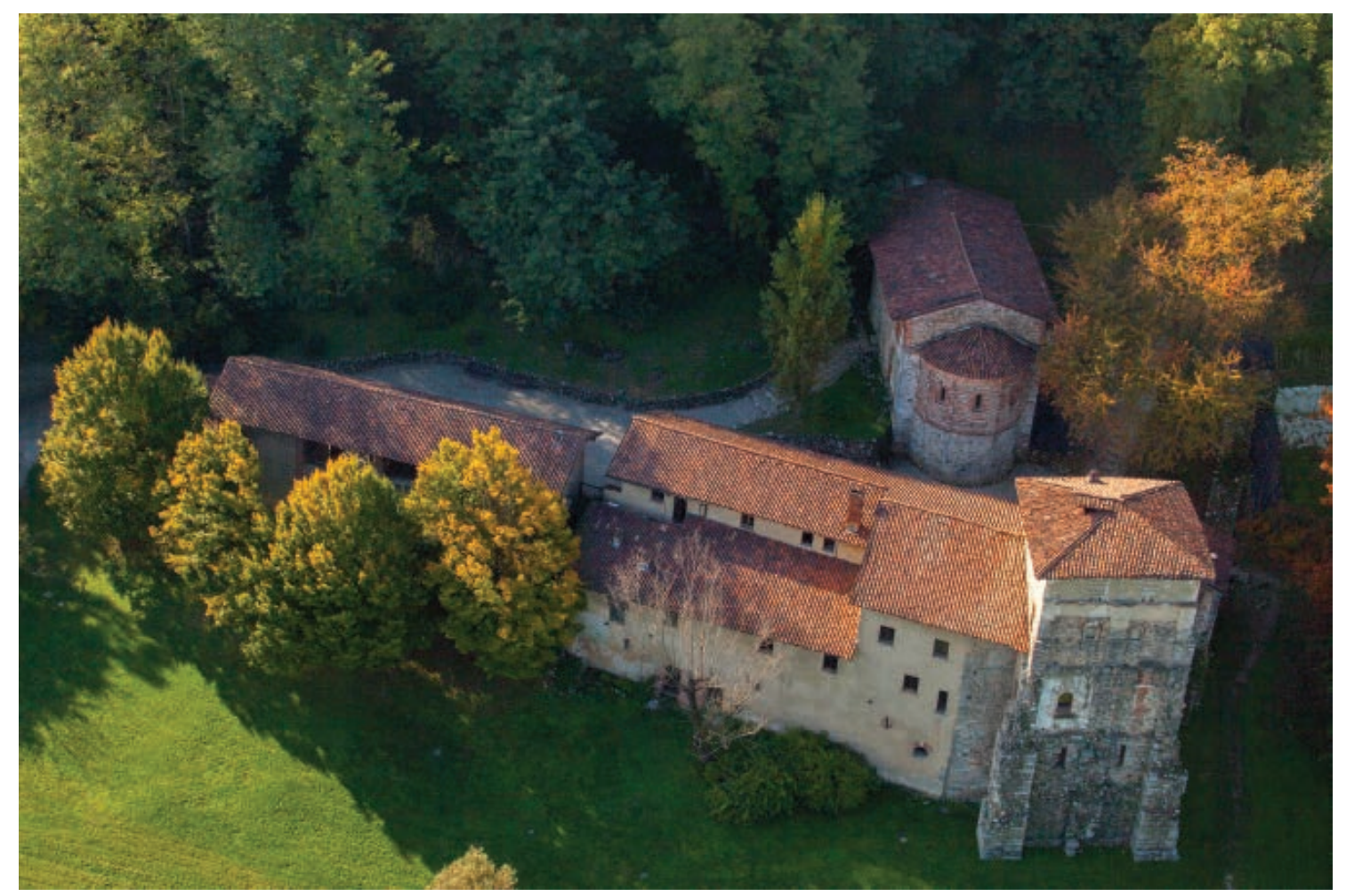

Fig. 7. Gornate Olona, località Torba, monastero di Santa Maria

Miscellanea cassinese" a cura dei monaci di Montecassino, "Studia Anselmiana" del Pontificio ateneo Sant'Anselmo di Roma, "Italia benedettina" del Centro storico benedettino italiano, "Vita monastica" dell'abbazia francese di Bellefontaine, "Scritti monastici" dell'abbazia italiana di Praglia, "Disciplina monastica. Studies on Medieval Monastic Life" e "Medieval Monastic Studies" edite da Brepols, "Vita Regularis. Ordnungen und Deutungen religiosen Lebens im Mittelalter" sostenuta dall'università di Dresda, "De re monastica" dalla Fondazione Centro italiano di studi sull'alto medioevo di Spoleto e così di seguito -, l'edizione di documenti e cartulari di cui ogni regione europea vanta una ricca produzione nazionale sui cenobi del proprio territorio, senza trascurare i repertori topo-bibliografici o Monasticon (Italiae, Anglicanum, Gallicanum, Belge, Hibernicum, ecc.) e le singole iniziative quali il "Monastic Matrix. A scholarly resource for the study of women's religious communities from the 400 to 1600 c.e." della Columbus University dell'Ohio, "The Hildemar Project" della Syracuse Universiy, i "Seminari sobre historia del monacato" promossi dalla Fundación Santa María la Real del Patrimonio Histórico de Aguilar de Campoo, giunti nel 2016 alla trentesima edizione, oppure l'edizione di typica curata dalla Byzantine Monastic Foun- dation Documents della Harward University di Washington, e così di seguito.

Pur evitando quindi di entrare nel mare magnum di questi materiali, come pure delle grandi collane di fonti medievali (Patrologia, Acta sanctorum, Monumenta Germaniae Historica, Sources chrétiennes, Corpus christianorum, Corpus scriptorum ecclesiasticorum, Die Griechischen Christlichen Schriftsteller, Corpus consuetudinum monasticarum, ecc.), un primo panorama d'insieme, è offerto dalle voci Vita quotidiana per il decimo tomo del Dizionario degli istituti di perfezione, quasi un centinaio di colonne - in cui si segnalano i contributi di Lisa Cremaschi, Adalbert de Vogüé e Albert d'Haenens - o Monachesimo cristiano di Vito Fumagalli per il quinto volume dell'Enciclopedia delle scienze sociali della Fondazione Treccani, Il cammino del monaco a cura di Luigi d'Ayala Valva e l'Introduzione di Enzo Bianchi alle Regole monastiche d'occidente ${ }^{14}$. Inoltre, utile punto di riferimento, sia per l'Oriente che per l'Occidente, possono essere gli atti del colloquio internazionale su Le temps chrétien de la fin de l'Antiquité au Moyen Âge, III'-XIII' siècle $^{15}$, seguito dal lavoro di Lucien Regnault per i padri del deserto ${ }^{16}$, dal commento di de Vogüé all'edizione della Regula Magistri, della Regula Benedicti e di altri testi normativi ${ }^{17}$ o dalla serie di contributi

${ }^{14}$ Cfr. la voce Vita quotidiana, in Dizionario degli istituti di perfezione, X, Roma 2003, coll. 366-455 (con particolare riferimento alle sezioni curate da L. CREMASCHI, parte I: I Padri del deserto, coll. 370-376; A. DE VOGÜÉ, parte II: Il primo monachesimo occidentale (sec. VI-VI), coll. 376-393; A. D'HAENENS, parte III: I Cistercensi, coll. 393-400) e quella di V. FUMAGALLI, Monachesimo cristiano, in Enciclopedia delle scienze sociali, V, Roma 1996, pp. 778-784; Il cammino del monaco. La vita monastica secondo la tradizione dei padri, cit.; E. BIANCHI, Introduzione, in Abitare come fratelli insieme. Regole monastiche d'occidente, Traduzione e note a cura di C. Falchini, Magnano (Bi) 2016, pp. 5-33. Preziosa è poi la bibliografia offerta dai singoli saggi raccolti in questo volume, sia per gli ambiti tematici che per le aree geografiche, a cui si rimanda per specifici approfondimenti.

${ }^{15}$ In cui sono raccolti gli atti del convegno parigino del 9-12 marzo 1981, Paris 1984 (Colloques internationaux du C.N.R.S., 604); utili anche i due volumi su La vie quotidienne des moines et chanoines réguliers au Moyen Âge et Temps modernes, Actes du Premier Colloque International du L.A.R.H.C.O.R. (Wrocław-Książ, 30 novembre - 4 décembre 1994), ed. M. Derwich, Wrocław 1995 (Travaux du L.A.R.H.C.O.R., Colloquia $1=$ Opera ad historiam monasticam spectantia. Series I, Colloquia 1); come pure i saggi di R. THOMAS, La jornada monástica según nuestros Padres, in Cistercium, 36 (1984), pp. 173-192; J. DUBOIS, La vie quotidienne dans les prieurés au Moyen Âge, in Prieurs et prieurés dans l'Occident médiéval, Geneve 1987, pp. 95-114.

${ }^{16}$ L. REGNAULT, La vie quotidienne des Pères du désert en Égypte au IVe siècle, Paris 1990; inoltre, J. BIARNE, La vie quotidienne des moines en Occident du IVe au VIe siècle, in Collectanea cistercensia, 49 (1987), pp. 3-19.

${ }^{17}$ Cfr. La Règle du Maître, Introduction, texte, traduction et notes par A. de Vogüé, I-II, Paris 1964 (SC 105-106); III: Concordance verbale du texte critique conforme à l'ortographe du manuscrit Pal. lat. 12205, edd. J.-M. Clément, J. Neufville, D. Demeslay, Paris 1965 (SC 107); La Règle de saint Benoît, cit., e vol. 
sul monachesimo cluniacense e da quelli sul cenobitismo inglese ${ }^{18}$ o presenti negli atti À la recherche de légitimités chrétiennes. Représentations de l'espace e du temps dans l'Espagne médiévale (IXe-XIII siècle $)^{19}$. Non mancano tuttavia robusti saggi con un taglio più divulgativo sulla vita monastica - come l'ormai classico lavoro di Leo Moulin e gli studi di Clifford Hugh Lawrence, Marcel Pacaut, Anselm Davril, Eric Palazzo, Ivan Gobry $^{20}$ e così via - e dedicati al computo delle ore, agli strumenti per calcolare il trascorrere del tempo (meridiane, clessidre, orologi) $)^{21}$ o caratterizzati da un approccio più spirituale e sociologico ${ }^{22}$, a cui vanno aggiunte le note di Giorgio Picasso, di chi scrive e di altrii ${ }^{23}$.

Il tema degli spazi monastici, d'altra parte, è al centro della serie di congressi internazionali della Fondazione Centro italiano di studi sull'alto medioevo di Spoleto, compresi sotto il titolo "De re monastica", diretti da Letizia Ermini Pani e giunti ormai alla sesta edizione ${ }^{24}$. Oggetto delle ricerche di ambito archeologico, come mostrano vari saggi editi nel presente volume, figurano an-

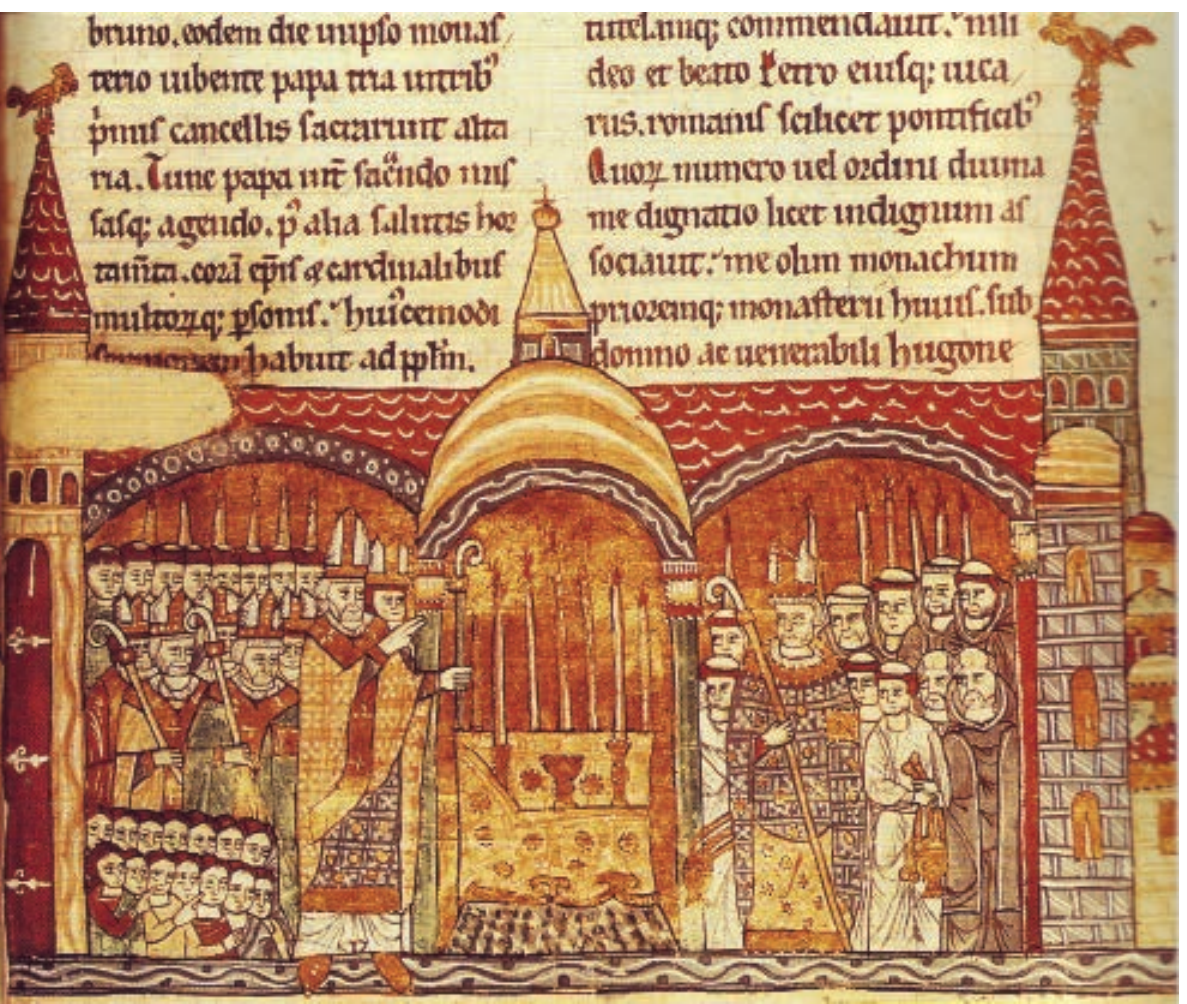
che in numerosi contributi sparsi in lavori miscellanei, quali per fare pochi esempi, Western Monasticism ante litteram. The Spaces of Monastic Observance in Late Antiquity and the Early Middle Ages, eds. Henrik Dey, Elizabeth Fentress,

Turnhout 2011; negli atti curati da Cécile Caby Espaces monastiques et espaces urbains de l'Antiquité tardive à la fin du Moyen Âge, Rome 2012 (Mélanges de l'École française de Rome. Moyen Âge, 124/1); nelle ricerche coordinate da

VII: Commentaire doctrinal et spirituel, ed. A. de Vogüé, Paris 1977; A. DE VOGÜÉ, L'horaire de l'Ordo monasterii. Ses rapports avec le monachisme égyptien, in Homo spiritualis. Festgabe L. Verhijen, Würburg 1987, pp. 240-258; IDEM, La comunità. Ordinamento e spiritualità, Abbazia di Praglia, Bresseo di Teolo (Pd) 1991 (Scritti monastici, 14).

${ }^{18}$ Per quanto la produzione su Cluny sia praticamente sterminata, si veda almeno il classico affresco di G. DE VALOUS, Le monachisme clunisien des origines au XVe siècle. Vie intérieure des monastères et organisation de l'Ordre, Paris 1970 e, per l'ambito inglese invece, B. HARVEY, Living and Dying in England, 1100-540: The Monastic Esperience, New York 1993.

${ }^{19} \mathrm{Si}$ tratta degli Actes du colloque tenu à Casa Velasquez (Madrid), 26-27 avril 2001, ed. P. Henriet, Lyon 2003 (Annexes des Cahiers de linguistique et de civilisation hispaniques médiévales, 15).

${ }^{20}$ Ma si tratta di un'esemplificazione del tutto indicativa, per cui cfr. L. MOULIN, La vita quotidiana dei monaci nel medioevo, Milano 1988; C.H. LAWRENCE, Il monachesimo medievale. Forme di vita religiosa in Occidente, Introduzione all'edizione italiana di G. Picasso, Cinisello Balsamo (Mi) 1993; M. PACAUT, Monaci e religiosi nel Medioevo, a cura di P. Bonacini, Bologna 2007² A. DAVRIL, E. PALAZZO, La vita dei monaci al tempo delle grandi abbazie, Cinisello Balsamo (Mi) 2002; I. GOBRY, Les moines en Occident, I. De saint Antoine à saint Basile. Les origines orientales, Paris 1985; II. De saint Martin à saint Benoît, Paris 1985; III. De saint Colomban à saint Boniface, Paris 1987; IV. De saint Benoît d'Aniane a saint Bruno. Le temps des conquêtes, Paris 2006; V. Le siècle de saint Bernard, I: Cîteaux, Paris 1997; VI. Le siècle de saint Bernard, II: Les ordres religieux autres que Cîteaux, Paris 2008; inoltre, cfr. anche E. MARIGLIANO, M. ZORZIN, Medioevo in monastero. Vita quotidiana in un'abbazia del XII secolo, Milano 2001; G.M. CANTARELLA, Lo spazio dei monaci, in Uomo e spazio nell'alto medioevo, Spoleto 2003 (Settimane di studio del Centro italiano di studi sull'Alto Medioevo 50), pp. 805-854; Monasteri in Europa occidentale (secoli VIII-XI): topografia e strutture, a cura di F. De Rubeis, F. Marazzi, Roma 2008.

${ }^{21}$ Più in generale, cfr. A. BORST, Computus. Tempo e numero nella storia d'Europa, Genova 1997 (I ed. Berlin 1990); N. SEVERINO, Le meridiane canoniche e il computo delle ore canoniche dei monaci del medioevo, in Rivista cistercense, 14 (1997), pp. 41-71; A. D’HAENENS, La clepsydre de Villers (1267). Comment on mesurait et vivait le temps dans une abbaye cistercienne au XIII e siècle, in Klösterliche Sachkultur des Spätmittelalters, Wien 1980 (Veröffentlichungen des Institut für mittelaterliche Realienkunde Österreichs, 3), pp. 321-342; F. CUSIMANO, "Nocturnos celebrandis cum galli cantu". I monaci, il tempo e l'astronomia, in Mediaeval Sophia, 10 (2011), pp. 104-122.

${ }^{22}$ Si veda per esempio il saggio di A. GRÜN, Nella dimensione del tempo dei monaci. Come vivere il tempo, Brescia 20o6, oppure A. D'HAENENS, Actualiser l'histoire de la vie quotidienne. Cléricalité, régularité et conventualité: trois concepts sociogénétiques pour une typologie de la quotidienneté scribale, in La vie quotidienne des moines et des chanoines, pp. 15-29.

${ }^{23}$ G. PICASSO, Il monaco e il tempo nella «Regula Benedicti», in Il tempo vissuto. Percezione, impiego, rappresentazione, Atti del convegno (Gargnano, 9-11 settembre 1985), Bologna 1988 (Studi e testi di storia medioevale, 16), pp. 39-46 e, nel medesimo volume, anche M. BETTELLI, Il tempo monastico in un documento bresciano del XV secolo, pp. 85-97 e L. SEBASTIANI, L'organizzazione del tempo nei monasteri femminili lombardi all'inizio dell'età moderna, pp. 99-107; G. PICASSO, Il sentimento del tempo nella tradizione monastica, in Sentimento del tempo e periodizzazione della storia nel Medioevo, Atti del convegno (Todi, 10-12 ottobre 1999), Spoleto 2000 (Atti dei convegni. Nuova serie, 13), pp. 199-212; G. ARCHETTI, "Nihil operi Dei praeponatur". Il tempo dei monaci nel Medioevo, in "Tempus mundi umbra aevi". Tempo e cultura del tempo tra Medioevo e età moderna, Atti dell'incontro nazionale di studio (Brescia, 29-30 marzo 2007), a cura di G. Archetti, A. Baronio, Brescia 2008 (Storia, cultura e società, 1), pp. 51-80.

${ }^{24}$ Editi nella collana "Incontri di studio", la serie dei congressi del "De re monastica" a cura di L. Ermini Pani, ha interessato i seguenti temi: I. Committenza, scelte insediative e organizzazione patrimoniale (Spoleto 2007); II. Cantieri e maestranze nell'Italia medievale, a cura di M.C. Somma (Spoleto 2009); III. Le valli dei monaci (Spoleto 2012); IV. Teoria e pratica del lavoro nel monachesimo altomedievale (Spoleto 2015); V. Gli spazi della vita comunitaria (Spoleto 2016). 
Michel Lauwers su Monastères et espace social. Gènese et transformation d'un systeme de lieux dans l'Occident médieval, Turnhout 2014 (Collection d'études médiévales de Nice, 15), fino all'ampio lavoro di Federico Marazzi, Le città dei monaci. Storia degli spazi che avvicinano a Dio, Milano 2015, a cui molti altri riferimenti possono essere aggiunti, come mostrano lo spoglio delle riviste di studi storici e gli indici stessi della collana Hortus Artium Medievalium per i cui curatori, nella sua più che ventennale attività scientifica, l'attenzione ai complessi claustrali è stata una costante.

\section{TEMPO E SPAZIO NELL'ASCESI MONASTICA}

Nell'esperienza monastica, sia anacoretica che comunitaria, nulla doveva essere anteposto all'opus Dei (RB 43,3) ricorda Benedetto (480-547) - che fa propria una tradizione più antica attestata nella Seconda Regola dei Padri, elaborata intorno al 427 probabilmente a Lérins ${ }^{25}$-, ma tutto veniva attentamente scandito dal tempo della preghiera, della lettura, del lavoro, del cibo, del sonno. Nihil asperum, però, nihil grave, «nulla di troppo austero o pesante» si sarebbero dovuti aspettare quanti militavano nella «scuola del servizio del Signore» (RB Prologo 45-46), perché quella benedettina era soltanto una «minima regula scritta per principianti» $(\mathrm{RB}$ $73,8)$. La giornata del monaco non contemplava infatti richieste insopportabili: otto ore circa di sonno d'inverno e sei nel periodo estivo, accompagnate da un riposo pomeridiano; razioni di cibo non abbondanti, ma sufficienti e variegate; sette ore di lavoro manuale e tre di lettura in estate, un po' meno durante l'inverno, e ben misurati periodi di astinenza per temperare i più aspri tempi del digiuno. Il tutto con un occhio di riguardo per l'infirmitas, fisica o morale, dei fratelli più deboli (RB 48,9).

La preghiera in comune, costituita dal canto in coro dell'ufficio divino, era l'esercizio peculiare di queste milizie oranti - così dev'essere intesa l'espressione scola dominici servitii, «la scuola del servizio del Signore» (RB Prologo 45), ossia del monastero ${ }^{26}$ - addestrate al combattimento spirituale e cinte delle «fortissime e gloriose armi dell'obbedienza» (RB Prologo 3). E lo divenne ancora di più quando, con la riforma carolingia, quel bilanciato equilibrio, composto di preghiera, lavoro e studio codificato dalla Regola, venne modificato per fare sempre più spazio all'ufficio divino e alla liturgia corale. «Non si deve credere - scriveva l'abate di Montecassino Teodomaro (778-797) al re Carlo - che si debba dispiacere al beato padre Benedetto, e anzi lo si dovrebbe piuttosto rallegrare, che qualcuno si preoccupi di aggiungere qualcosa a ciò che lui aveva ordinato per le lodi divine $»^{27}$. L'accrescersi del tempo per la preghiera, inoltre, venne rafforzato dall'idea che la perfetta esecuzione della

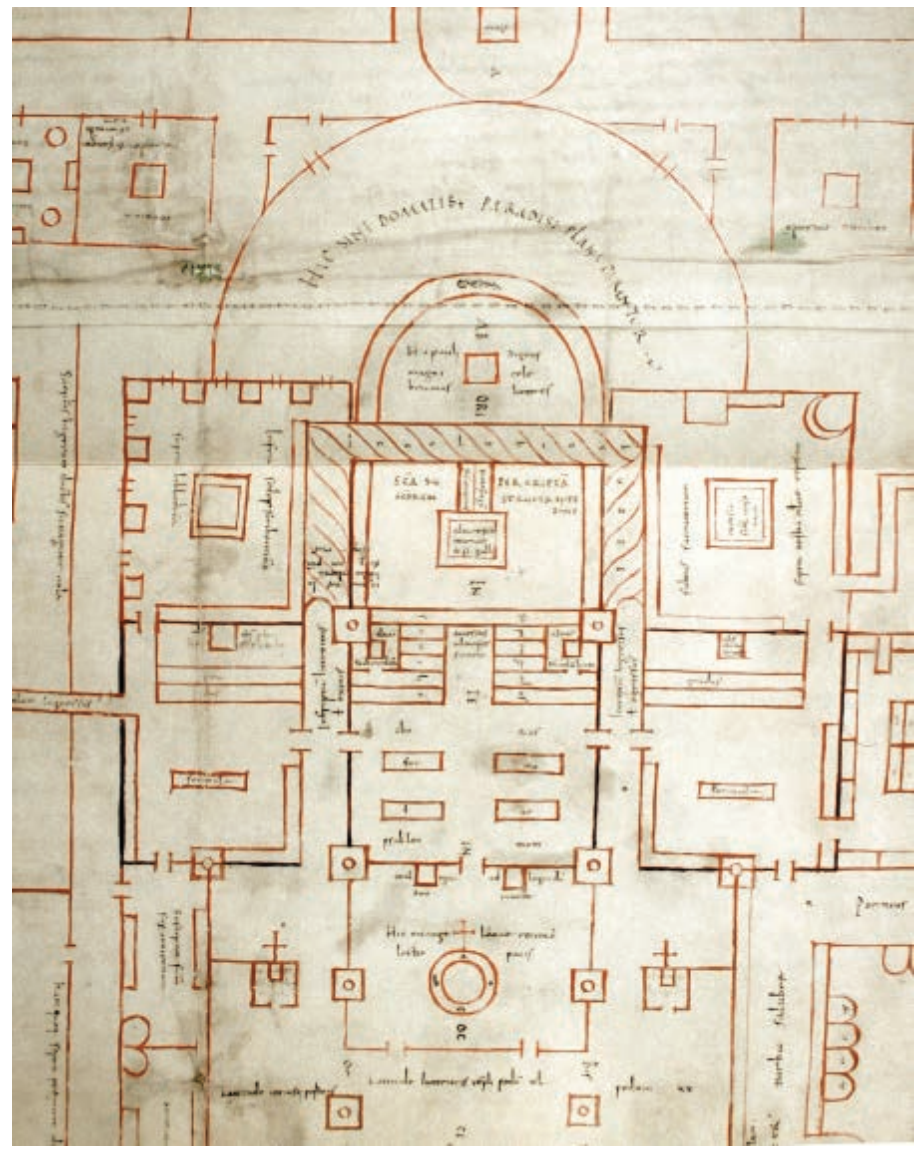

Fig. 9. San Gallo, Stiftsbibliothek, ms 1092, pianta del monastero di San Gallo, particolare della chiesa monastica e del coro, 816-837

liturgia, non solo era un dovere dei cenobiti, ma coincideva con le aspettative spirituali dei loro benefattori e protettori laici, per i quali quell'incessante flusso di orazioni era recepito alla stregua di un salvacondotto per la vita eterna (fig. 8).

Tutto questo appare chiaro nella legislazione di Benedetto di Aniane († 821), l'ispiratore della svolta riformatrice di Aquisgrana, le cui ricadute pratiche sull'orario claustrale vengono descritte con cura dal suo biografo: «Egli introdusse per la prima volta - scrive Ardo Smaragdo in un lungo passo della Vita del riformatore franco, in cui si illustra l'impegno liturgico dei monaci -, avanti che fosse fatto suonare il segnale delle ore notturne, l'uso di far squillare una campanella nel dormitorio dei fratelli, in modo che i monaci che dormivano potessero raggiungere prima i propri stalli per le preghiere e successivamente, spalancate le porte della chiesa, si facessero entrare gli ospiti. Ordinò che i confratelli, alzatisi in fretta, come la regola prescrive, si aspergessero con l'acqua santa e con umiltà e rispetto passassero davanti a tutti gli altari, poi si sedessero ai propri posti per essere pronti ad

\footnotetext{
${ }_{25}$ Il riferimento testuale è il recupero, da parte di san Benedetto, di una tradizione più antica, presente nella Seconda Regola dei Padri, elaborata probabilmente a Lérins verso il 427, dove parlando dell'ora della preghiera se ne precisa la funzione prioritaria [J. NEUFVILLE, Règle des IV Pères et Seconde Règle. Texte critique, in Revue bénédictine, 75 (1965), pp. 75-95 per le due regole; anche G. TURBESSI, Regole monastiche antiche, Roma 1990 (Religione e società. Storia della Chiesa e dei movimenti cattolici, 15), p. 333, cap. 31: «non si deve anteporre nulla alla preghiera»; Abitare come fratelli insieme, pp. 247-248, cap. 14,3]; riguardo al posto d'onore invece riservato da Benedetto all'opus Dei, collocata prima di qualunque altra occupazione, e quindi alla funzione fondamentale della salmodia e dell'orazione per i monaci, cfr. A. DE VOGÜÉ, San Benedetto, l'uomo e l'opera, Abbazia di San Benedetto, Seregno (Mi) 2001 (Orizzonti monastici, 27), pp. 87-99, 118-119.

${ }^{26}$ Sul concetto di schola si veda l'ampio commento, a corredo del passo benedettino, di A. DE VOGÜÉ, La Regola di san Benedetto. Commento dottrinale e spirituale, Abbazia di Praglia, Bresseo di Teolo (Pd) 1984 (Scritti monastici, 5), pp. 31-67; IDEM, San Benedetto, pp. 68-70, 72-73.

${ }^{27}$ Epistulae variorum Carolo Magno regnante scriptae, in MGH, Epistulae Karolini aevi, ed. E. Dümmler, IV, t. II, Berolini 1895, p. 511, epist. 13 (a. 789-797); Theodomari abbatis Casinensis epistula ad Karolum regem, ed. D.K. Hallinger, D.K. Wegener, in Initia consuetudinis benedictinae. Consuetudines saeculi octavi et noni, Siegburg 1963 (Corpus consuetudinum monasticarum, 1), p. 160. L'ordo dell'abate Angilberto († 814) di Saint-Riquier, per esempio, prevedeva tre cori monastici, ognuno dei quali contava cento monaci e trecentoquattro ragazzi, litanie, processioni solenni, e la celebrazione di almeno trenta messe al giorno in diversi altari (F. LOT, Chronique de l'abbaye de Saint-Riquier, Collection de textes, Paris 1894, pp. 70-71).
} 
alzarsi, al terzo segnale ${ }^{28}$, in attesa del sacerdote designato a cominciare il rito. E nessuno di coloro, a cui era imposto di entrare in chiesa, potesse sostare durante questo tempo negli angoli della basilica, ma tutti recitassero mentalmente i salmi stabiliti seduti nel coro $»^{29}$ (fig. 9).

Il cronista si sofferma quindi ad illustrare come si articolava, quali erano le finalità e l'atteggiamento del monaco durante la salmodia corale: «Ordinò poi di cantare i salmi: cinque per tutti i fedeli viventi nel mondo, cinque per tutti i defunti e altrettanti per coloro che erano morti da molto tempo, ma la notizia del cui decesso non a tutti ancora era nota. Dopo aver recitato ciascun gruppo di cinque salmi, il monaco si prostri in preghiera, raccomandando a Dio coloro per i quali ha cantato quei salmi e poi iniziando a pregare per gli altri. L'uomo devoto non deve essere pigro; con salmodie precise e fisse deve supplicare l'eterno re con il corpo prostrato a terra, poiché non si sottopone ad ogni parola dei potenti chi ha imparato a prostrarsi davanti a Dio, ma soprattutto perché in questo modo si richiede la grazia divina e si suscita il fervore della compunzione» ${ }^{30}$.

Di seguito presenta la scansione giornaliera della liturgia delle ore e le sue variazioni nel corso dell'anno: «Nel periodo estivo, dopo aver portato a termine l'ufficio delle Lodi mattutine, Benedetto ordinò che i monaci subito uscissero dalla chiesa per evitare la sonnolenza e, messisi le scarpe e lavatisi il volto, in fretta facessero di nuovo ritorno verso la chiesa e, secondo l'ordine già detto, passassero davanti agli altari con riverenza e si aspergessero con l'acqua santa, dirigendosi in seguito ai posti prestabiliti per recitare con sincera disposizione l'ufficio diurno. Stabili che questa liturgia si sarebbe conclusa, conformemente al rito romano, con il salmo 118, e che, suonato il segnale dell'ora prima, i monaci fossero pronti a recarsi in coro. Inoltre ordinò di suonare il segnale così a lungo che tutti potessero accorrere durante il suo squillo e al suo cessare il sacerdote iniziasse la liturgia.

Conclusa l'ora Prima, riuniti insieme, i monaci dovevano dire un versetto del salmo, e quindi, in silenzio o cantando i salmi, recarsi al proprio lavoro. Coloro che rimanevano nel monastero non dovevano intrattenersi con discorsi inutili, ma due alla volta, o da soli, cantare i salmi in cucina, nel mulino, nella cantina. Stabilì che dopo compieta nessuno uscisse o rimanesse arbitrariamente in oratorio, ma che d'inverno prima cantassero dieci salmi, d'estate cinque; dato il segnale, tutti contemporaneamente, secondo le modalità consuete, passassero davanti ai diversi altari e poi uno dopo l'altro si dirigessero verso i loro letti per coricarsi. Prescrisse infatti di fare il giro intorno agli altari ogni giorno, in tre momenti diversi, e nel primo di questi ordinò che recitassero l'orazione insegnata dal Signore e la professione di fede, negli altri il Padre nostro o confessassero le proprie colpe».
L'abate riformatore franco ordinò infine che, «nelle ore diurne di orazione, per pregare i fratelli accedessero al proprio posto; se però qualcuno voleva pregare per conto proprio, era libero di farlo in qualsiasi momento». E conclude osservando che «il padre Benedetto stabilì questi tre cicli di preghiera, affinché coloro che erano pigri e si rifiutavano di pregare, fossero costretti a compiere ciò che non volevano fare spontaneamente e non potessero assentarsi nelle ore prestabilite; coloro che invece ardevano da eccessivo amore per la preghiera fossero trattenuti dal pregare ulteriormente, senza alcun equilibrio. Spesso, infatti, accade che i monaci siano spossati da una sola, ma estenuante, veglia notturna, e che poi, nelle ore in cui vi è da dedicarsi alla salmodia, pieni di sonno, non riescano ad assolvere il loro dovere spirituale» $3^{3}$.

Un passo quest'ultimo dove è evidente l'intento del biografo del santo monaco di Aniane di dare conto di una virtù tipica della tradizione ascetica, sia orientale che occidentale, connessa con la direzione e la capacità di discernimento dell'abate o del maestro (discretio). Ciò è interessante perché, di fronte alla tentazione della ricerca di una via straordinaria, caratterizzata da forme di rigorismo eroico e ai limiti di ogni sopportazione - eccessi, deviazioni, stranezze, fughe dalla realtà hanno alimentato i monaci di ieri e di oggi -, l'insegnamento che viene dalla storia monastica, sin dai Padri del deserto, è quello di vivere il desiderio di Dio nell'obbedienza e nella semplicità, considerando prodigioso e straordinario solo la carità del servizio vicendevole e della comunione fraterna ( $R B$ 35,6). Un insegnamento che tocca il cuore della spiritualità evangelica e permette ai monaci, perseveranti nella loro scelta fino alla morte, di «partecipare alle sofferenze di Cristo» meritando così la gioia eterna (RB Prologo 50), dal momento che la loro ricerca di silenzio e di interiorità non è assimilabile a quella della tradizione filosofica o della sapienza antica, ma coincide con l'imitazione del Signore in croce attraverso l'offerta della propria vita nell'osservanza regolare.

\section{NELLA SOLITUDINE DEL DESERTO}

La giornata del monaco egiziano, quella descritta dai Padri del deserto, trascorreva in origine per lo più entro le mura della propria cella, che, soltanto in un secondo momento, andò articolandosi in vari ambienti, chiusi da un muro di cinta, dove potevano esserci uno o più spazi per i discepoli. Ciascun monaco seguiva un proprio stile di comportamento, in obbedienza al padre spirituale che lo guidava a trovare ritmi di lavoro e di preghiera confacenti al suo cammino di perfezione. Nulla di stabilmente definito, dunque, né istituzionalmente organizzato, ma grande varietà e autonomia di forme come scrive Girolamo (342 ca.-420) ${ }^{32}$ o racconta

\footnotetext{
${ }^{28}$ Per questo triplice suono del segnale cfr. Ildemaro, p. 322, che conferma il racconto di Ardo Smaragdo e, a proposito di RB 22,5: "La preghiera comunitaria, tuttavia, sia assolutamente breve, e al segno dato dal superiore tutti si alzino insieme", spiega: «di notte il fratello sente il primo segnale e velocemente va in chiesa e prega davanti agli altari; in seguito, sta in qualche angolo o seduto al suo posto e, udito il secondo segnale, sta pronto; quando poi sente il terzo segnale, se è seduto, deve alzarsi o venire in coro stando preparato a quando si dice Deus in adiutorium», cioè prende inizio la liturgia comunitaria.

${ }^{29}$ ARDO SMARAGDO, Vita Benedicti abbatis Anianensis et Indensis, ed. G. Waitz, in MGH, Scriptores, XV/1, Stuttgart 1963, p. 216, cap. 38.

$3^{\circ}$ ARDO SMARAGDO, Vita Benedicti, p. 216. La preghiera di compunzione, o cum lacrimis, è un tema ricorrente nella tradizione monastica antica e medievale (P. ADNÈS, s.v., Larmes, in Dictionnaire de spiritualité, IX, Paris 1976, coll. 295-303), cfr. RB 4,57; 20,3; 52,4; e 49,4 dove si distingue tra «oratio cum fletibus» e «compunctio cordis» da intendere, quest'ultima, come il sentimento di dolore dovuto alla consapevolezza della propria indegnità morale (DE VOGÜÉ, La Regola di san Benedetto, pp. 349-357). Per san Benedetto l'ideale spirituale a cui tendere è la gioia dello Spirito che effonde nell'anima mediante la penitenza fisica e l'umile attesa dell'eternità (RB 49,6-7; 4,46).

${ }^{31}$ ARDO SMARAGDO, Vita Benedicti, pp. 216-217; anche Ildemaro, pp. 306-308; inoltre, ARCHETTI, "Nihil operi Dei praeponatur", pp. 52-55.

${ }^{32}$ GIROLAMO, Epistulae, ed. I. Hilberg, I, Vindobonae 1996 (Corpus scriptorum ecclesiasticorum latinorum, 54), pp. 196-201, epist. 22,34-36; distinzione ripresa anche da Benedetto che parla però di quattro tipi di monaci: cenobiti, anacoreti o eremiti, sarabaiti e girovaghi (RB 1,1-6; e la corrispondenza in RM 1; per i diversi tipi di monaci anche Il cammino del monaco, pp. 75-79).
} 


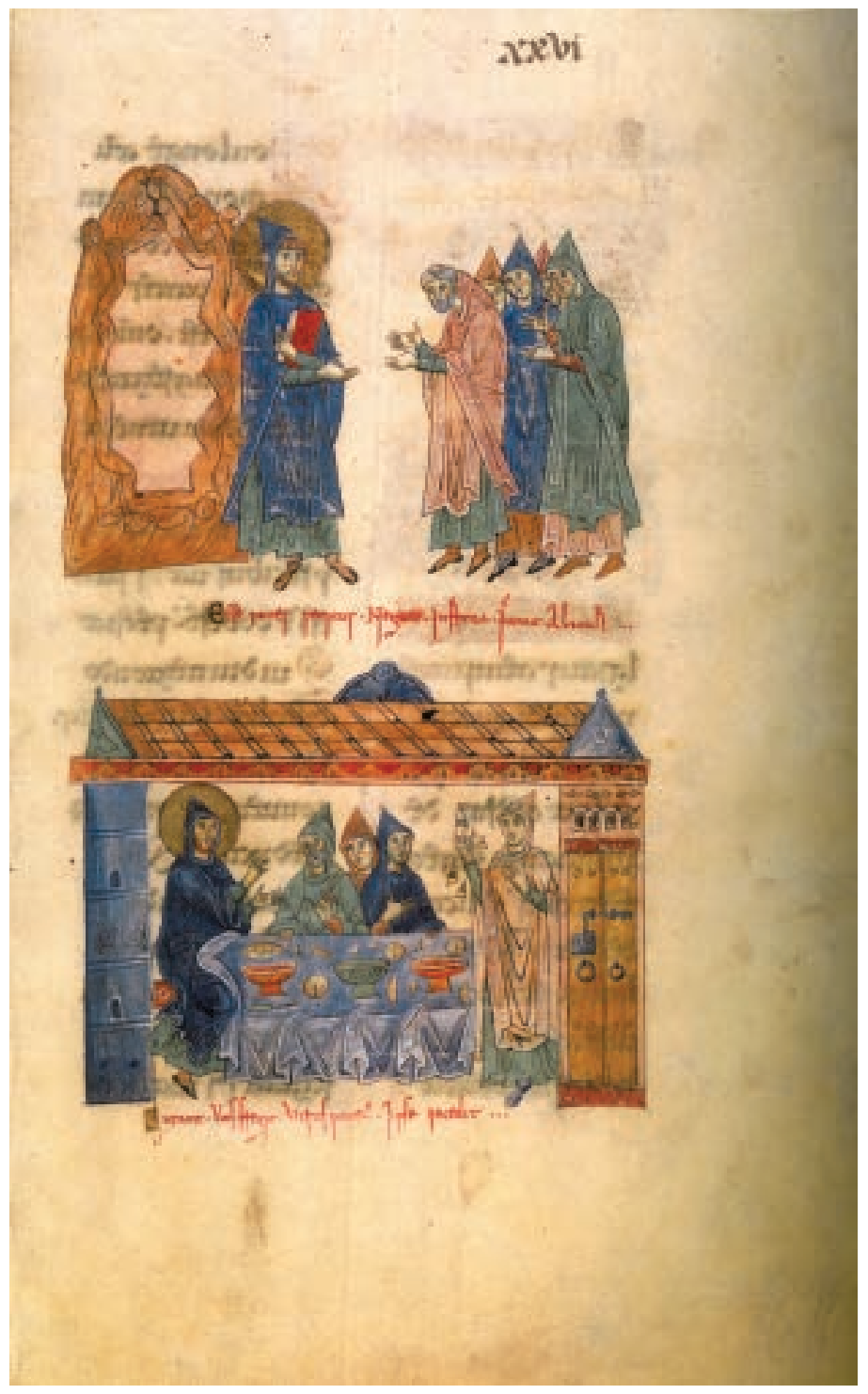

Fig. 10. Biblioteca Apostolica Vaticana, ms Vat. Lat. 1202, f. 26r, Lezionario di Desiderio, scene di vita di san Benedetto, 1071 circa

Gregorio di Nazianzo (328-39o) a proposito dei monasteri egiziani in cui gli uomini vivevano «solo per Dio» lontani dal mondo: alcuni facevano «una vita solitaria e completamente separata dalla società dei loro simili, godendo del colloquio con Dio e con se stessi», altri invece «vivendo nella carità, al contempo come eremiti e cenobiti»33 (figg. 10, 11).

L'organizzazione della giornata secondo un orario preciso, pertanto, si ebbe solamente con la nascita del monachesimo cenobitico, che andò codificando in regole scritte i ritmi quotidiani dei fratelli. La disciplina del tempo nella primitiva anacoresi veniva, di conseguenza, adattata alle esigenze dei singoli asceti, la cui giornata iniziava e terminava con la pre-

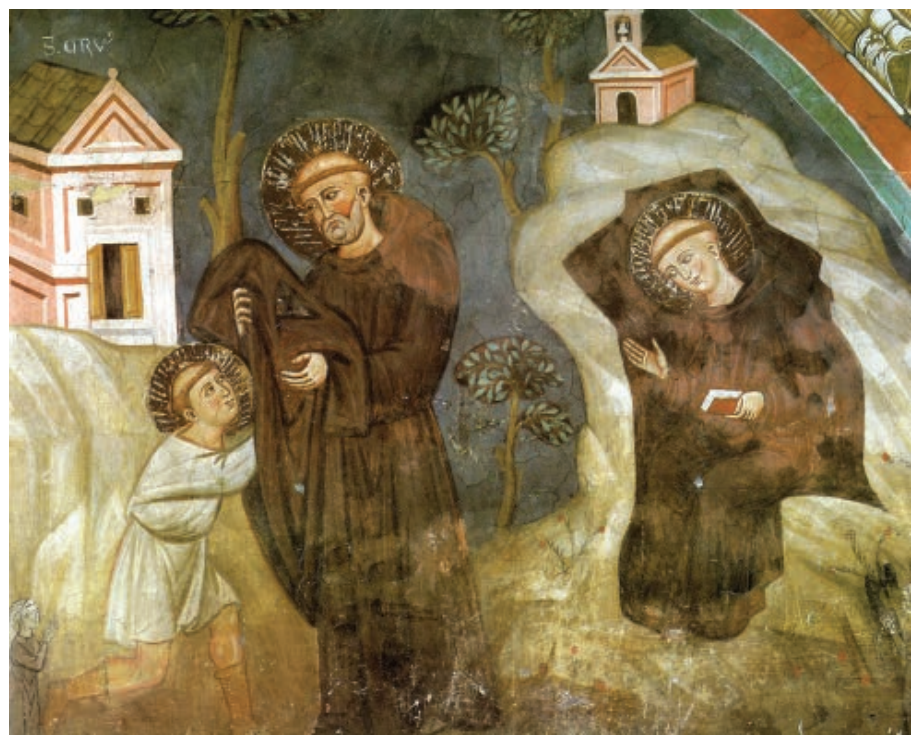

Fig. 11. Subiaco, Sacro Speco, chiesa inferiore, storie di San Benedetto: vestizione e ritiro entro la grotta, seconda metà XIII secolo

ghiera. «Quando ti alzi dopo aver dormito - si legge tra i Detti dei Padri del deserto -, per prima cosa la tua bocca renderà subito gloria a Dio. Dovrà intonare inni e salmi perché lo spirito continui a macinare per tutto il giorno come una mola il primo pensiero al quale si è attaccato fin dall'aurora» ${ }^{34}$. Anche nelle comunità basiliane (figg. 12, 13), in un contesto più urbano e ormai codificato, i tempi della preghiera erano ben scanditi «perché ciascuno ha una memoria particolare dei beni ricevuti da Dio»35 e Basilio di Cesarea (330 ca.-379) ricorda che la preghiera va fatta al sorgere del giorno «per consacrare a Dio i primi moti dell'anima» e prima di mettersi al lavoro; poi è bene che la comunità si riunisca per pregare all'ora terza, interrompendo gli impegni di ciascuno; a sesta per allontanare le tentazioni del «demonio di mezzogiorno», quindi a nona e al termine della giornata per ringraziare Dio «di quanto ricevuto». All'inizio della notte l'orazione si elevava di nuovo per chiedere un sonno tranquillo ed era ripetuta nel mezzo delle ore notturne; quindi si tornava a pregare prima dell'aurora per scongiurare che il giorno potesse sorprendere i monaci ancora nel sonno o appisolati nel letto ${ }^{36}$.

Nell'omelia per la martire Giuditta, commentando con forte lirismo un passo della prima lettera ai Corinti $(10,31)$, Basilio esorta il monaco ad avere un comportamento e sentimenti di gratitudine continua: «Seduto a tavola, prega; portando il pane alla bocca, ringrazia chi te lo dà; sostenendo con il vino la debolezza del corpo, ricordati di chi ti fa questo dono per la gioia del tuo cuore». La sua esortazione assume poi i toni di una lode cosmica: «Quando il bisogno degli alimenti è finito, che non finisca il ricordo del benefattore.

\footnotetext{
33 «Essi sono morti agli altri uomini - prosegue Gregorio Nazianzeno - ed agli affari temporali che si trattano di solito e ci deridono per tutte le nostre preoccupazioni, ma tra loro sono l'uno con l'altro socievoli e stimolano ed accrescono la loro virtù gareggiando vicendevolmente» (GREGORIO DI NAZIANZO, Discorso in lode di sant'Atanasio, in Fonti e studi di storia della Chiesa, a cura di P. Brezzi, Milano 1962, p. 1056).

${ }^{34}$ Detti inediti dei Padri del deserto, Introduzione, traduzione e note a cura di L. Cremaschi della Comunità di Bose, Magnano (Bi) 1986, p. 242; inoltre, CREMASCHI, I Padri del deserto, col. 372.

${ }_{35}$ BASILIO DI CESAREA, Le regole. Regulae fusius tractatae - Regulae brevius tractatae, Introduzione, traduzione e note a cura di L. Cremaschi della Comunità di Bose, Magnano (Bi) 1993, p. 180 e, per le citazioni successive, pp. 180-182; sulle comunità basiliane, v. L. CREMASCHI, La vita comune secondo Basilio, in Basilio tra Oriente e Occidente, Convegno internazionale "Basilio il Grande e il monachesimo orientale", Cappadocia, 5-7 ottobre 1999, a cura della Comunità di Bose, Magnano (Bi) 2001 (Spiritualità orientale), pp. 93-110.

${ }^{36}$ BASILIO DI CESAREA, Le regole, pp. 181-182. Sull'influsso e l'immagine di Basilio sul monachesimo occidentale altomedievale, cfr. A. DE VOGÜÉ, L’influenza di Basilio sul monachesimo occidentale, e R. GRÉGOIRE, Una lettura carolingia di Basilio: la «Concordia delle regole» di Benedetto di Aniane, in Basilio tra Oriente e Occidente, rispettivamente pp. 209-224 e 225-234.
} 


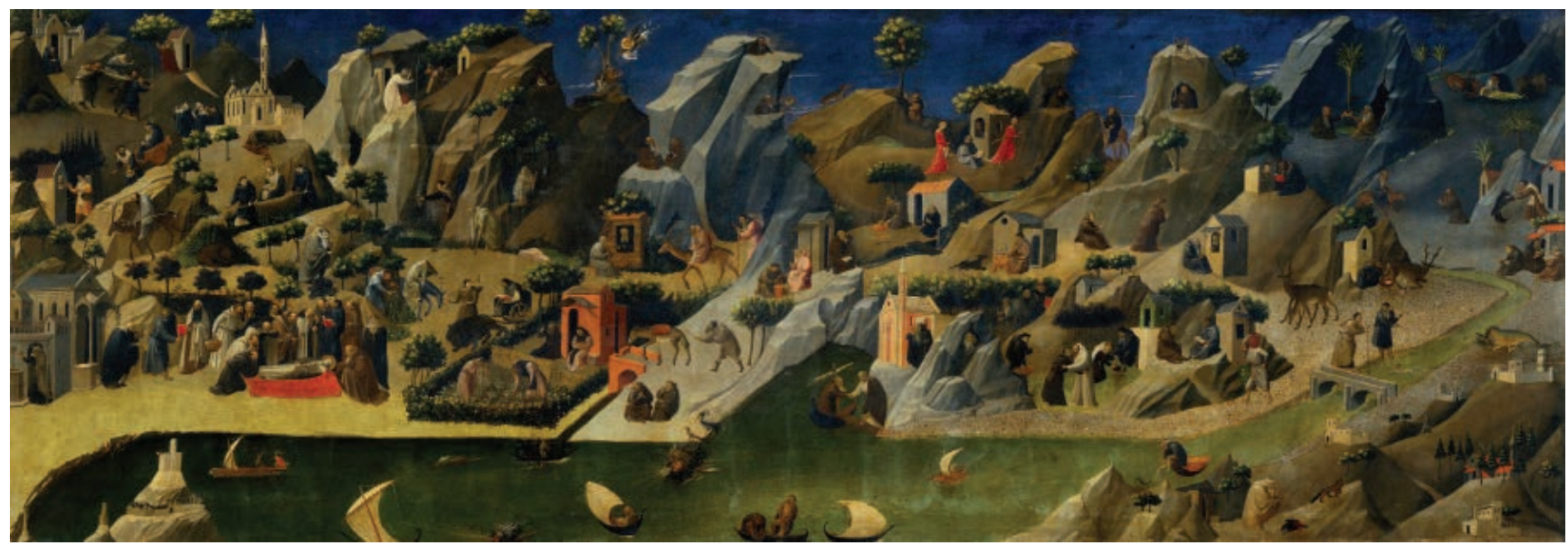

Fig. 13. Firenze, Galleria degli Uffizi, Tebaide, opera di Beato Angelico, 1418-20

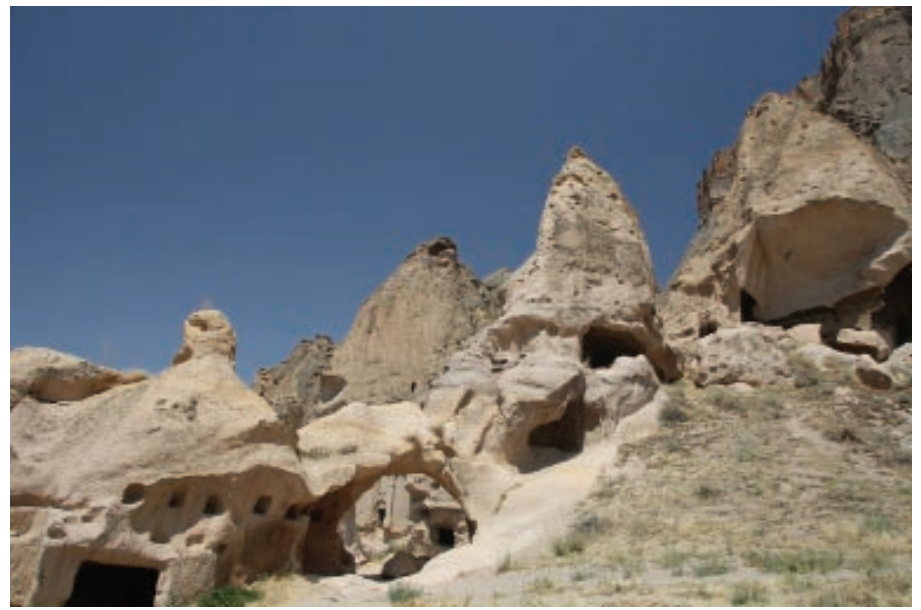

Fig. 12. Cappadocia, monastero di Selime

Indossando la tunica, ringrazia chi te la dà; aggiungendovi il mantello, accresci l'amore di Dio», e prosegue: «Quando il giorno è passato, ringrazia chi ci accorda il sole per illuminare l'attività diurna e il fuoco per rischiarare la notte e mettersi al servizio di tutte le nostre necessità» ${ }^{37}$.

Ma le ore notturne recavano altri argomenti di preghiera: «Quando levi lo sguardo verso la bellezza del cielo stellato, prega il Signore delle cose visibili, adora l'artista che nella sua saggezza ha creato l'universo. Quando vedi tutta la natura animale immersa nel sonno, adora di nuovo chi per mezzo del sonno ci libera, anche senza che noi ne siamo coscienti, dalla catena delle fatiche e con un po' di riposo ricostituisce il vigore delle nostre forze. Di conseguenza la notte non sia interamente riservata all'assopimento; non lasciare l'incoscienza occupare inutilmente metà della vita. Il tempo della notte sia diviso in riposo e preghiera; o, piuttosto, il sonno stesso rimanga una santa meditazione. Il più delle volte i sogni sono l'eco delle preoccupazioni del giorno. Quali le preoccupazioni della vita, tali i sogni. Così, prega senza posa; non si tratta di compiere la preghiera con parole incessanti, ma di unirti a Dio con tutto l'atteggiamento della tua vita, e tutta la tua vita sarà una preghiera continua e ininterrotta» $3^{8}$.

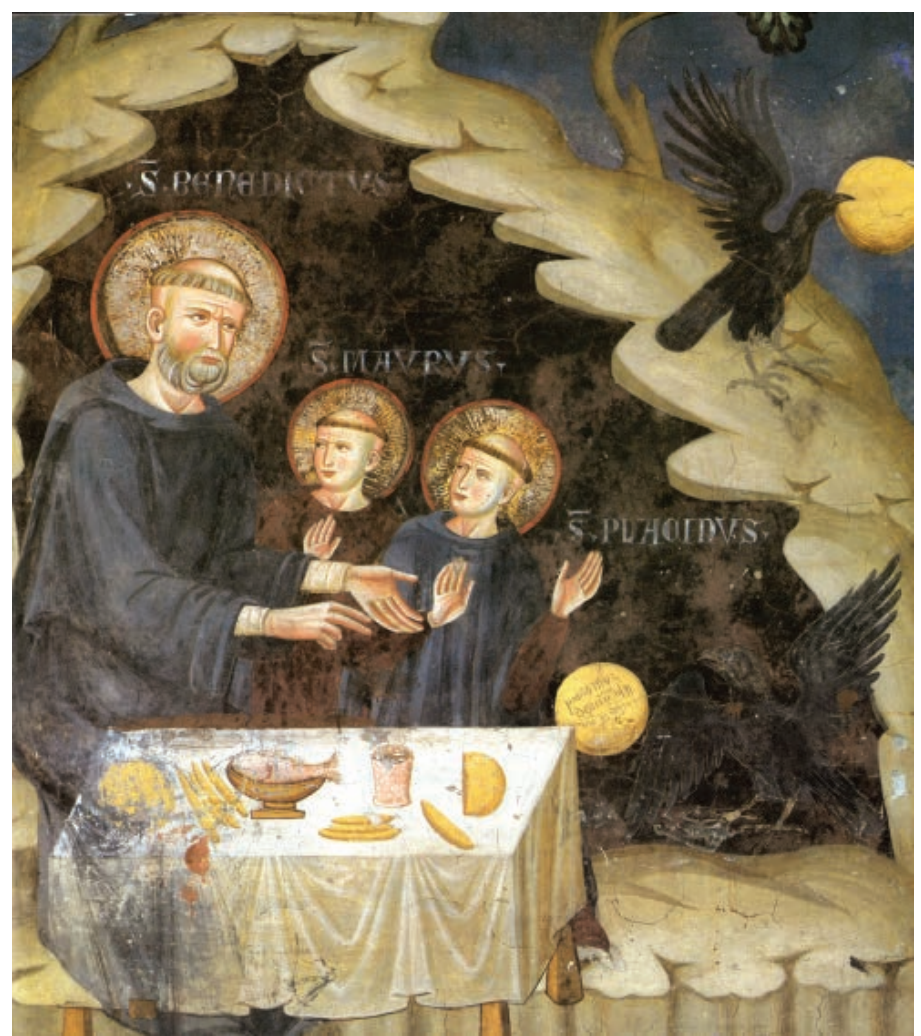

Fig. 14. Subiaco, Sacro Speco, chiesa inferiore, storie di San Benedetto: sottrazione del pane avvelenato ad opera del corvo, seconda metà XIII secolo

Per consentire la continuità dell'azione orante bisognava conoscere il salterio e i testi sacri a memoria: «Dobbiamo ruminare il buon cibo e non quello cattivo. Cibo proficuo sono i buoni pensieri offerti dalla tradizione dei santi maestri e dalla lettura delle Scritture; l'anima di chi ama Dio deve sempre meditarli»39 (fig. 14). Antonio chiedeva ai discepoli di apprendere a memoria i precetti delle Scritture, Pacomio (292-346) esigeva dai monaci di imparare a leggere e, a quanti intendevano abbracciare la vita monastica, di conoscere il Padre nostro e un certo numero di salmi, mentre Palladio narra che Marco l'asceta, Erone e Serapione sapevano a memoria la Bibbia ${ }^{40}$. In questo modo diventava possibile meditare e

37 BASILIO DI CESAREA, Homilia in martyrem Iulittam, in Patrologia graeca, 31, col. 244.

$3^{8}$ BASILIO DI CESAREA, Homilia in martyrem Iulittam, col. 244

${ }^{39}$ Detti inediti, pp. 304-305.

${ }^{40}$ Se nel monachesimo pacomiano è prevista la lettura quotidiana delle Scritture, tra i padri del deserto raramente essa viene ricordata tra le occupazioni abituali del monaco, mentre il possesso di libri è giudicato una grande ricchezza benché - sovente - per lo più poco utile ai fratelli che, essendo spesso analfabeti, non sapevano leggere (CREMASCHI, I Padri del deserto, col. 372). Per la legislazione pacomiana, v. Precetti 49; per la Vita di Antonio [cap. 53,3, 
pregare anche durante il lavoro o quando le contingenze del vivere prevalevano ${ }^{41}$. L'esercizio dell'apprendimento mnemonico però, fatto attraverso la pratica della lettura, non era uniformemente diffuso, come non lo erano i libri - la cui presenza nel cenobio presupponeva comunque la capacità di comprenderne il contenuto, un fatto tutt'altro che scontato-, mentre era basilare la mediazione del maestro e il confronto periodico con gli asceti della regione.

Per quanto poi la tentazione di vivere alla maniera degli angeli fosse una costante per il monaco ${ }^{42}$, la sua condizione materiale non lo esonerava dal lavoro manuale, né dalla fatica fisica, attraverso cui procurava il sostentamento per sé, mentre il surplus serviva per la carità fraterna e per i poveri. Atanasio racconta che Antonio «lavorava con le sue mani, poiché aveva udito: Chi vive nell'ozio non mangi (2 Ts 3,10). Parte del suo lavoro gli serviva per procurarsi il pane, parte lo distribuiva ai poveri» ${ }^{43}$. Il lavoro però - come non doveva essere sostituito dalla preghiera, ma diventare esso stesso orazione e ascesi ${ }^{44}$ - non era un fine, né uno strumento di alienazione, poiché «l'attaccamento eccessivo al lavoro - sentenziavano i Padri - è rovina dell'anima, ma un lavoro ordinato dona riposo in Dio» ${ }^{45}$; di un anziano si dice che intrecciava corde e poi le gettava via: «lavorava, infatti, non perché ne avesse bisogno, ma per faticare e acquistare la pace» ${ }^{4}$. E Basilio osserva che in questo modo si rende grazie a Dio, che «ha dato la forza delle mani per lavorare e una mente sapiente per acquistare la scienza e ci ha fatto dono anche della materia, sia quella da cui si ricavano gli arnesi da lavoro, sia quella che lavoriamo nelle diverse arti» ${ }^{47}$. Ma il lavoro manuale, continua il vescovo di Cesarea, mediante la preghiera contribuisce a realizzare la vocazione monastica di piacere a Dio.

Anche per il sonno come per il cibo non vi erano regole precise, molto dipendeva dal temperamento personale, dai tempi e dai luoghi: «meglio bere vino con discernimento che acqua con vanità», osserva Palladio e Pacomio racconta di aver appreso da Palamone tre diversi modi di vegliare: risvegliarsi a metà della notte, ritardare di un poco il sonno o anticipare il risveglio ${ }^{48}$. Discrezione e discernimento erano perciò la via aurea da seguire; ma, ancora una volta, sono la pluralità delle esperienze concrete a prevalere e gli indirizzi ascetici dettati dai singoli maestri a costituire l'elemento comune della via della perfezione nella solitudine del deserto. Parole di riconoscenza per il fratello incaricato di dare la sveglia sono espresse da Basilio, perché «quando si dorme l'anima non ha più coscienza neppure di se stessa»49, il quale riconosce nella temperanza la misura vera del cibo, sia riguardo alla varietà alimentare che all'orario per nutrirsi, evitando però «quanto porta al piacere» che è «fonte di rovina» ${ }^{\circ}$.

Scambi fraterni, infine, avvenivano in occasione della celebrazione eucaristica festiva o domenicale, come pure

in ATANASIO DI ALESSANDRIA, Vita Antonii, ed. G.J.M. Bartelink, Paris 1994 (SC 40o), p. 176]; per PALLADIO, La Storia Lausiaca, edd. C. Mohrmann, G.J.M. Bartelink, M. Barchieri, Milano 1974, pp. 93, 161, 183, capp. 18, 25; 32, 12; 37, 1.

${ }^{41} \mathrm{Nel}$ deserto egiziano era prassi diffusa imparare a memoria i salmi e interi libri della Scrittura; ciò aiutava la preghiera incessante nel corso della giornata, meditando la parola di Dio nel proprio cuore. Le regole pacomiane esortano il monaco a meditare mentre cammina (Precetti 3; 28; 59; Regolamenti 13-14), mentre dà il segnale per il pasto (Precetti 36; 196), distribuisce il cibo ai fratelli (Precetti 37) o lavora (Precetti 6o; 116; Regolamenti 39; 44-47). Nel monastero palestinese fondato da Epifanio, vescovo di Cipro (secolo IV), si racconta che l'abate avesse mandato a dire al presule che - grazie alle sue preghiere - i monaci non avevano mai trascurato la regola e celebrato con zelo l'ora prima, terza, sesta, nona e l'ufficio del lucernario; ma Epifanio gli rispose rimproverandolo con queste parole: «Evidentemente trascurate le altre ore del giorno astenendovi dalla preghiera. Il vero monaco deve avere incessantemente nel cuore la preghiera e la salmodia» (Vita e detti dei Padri del deserto, a cura di L. Mortari, Roma 1996, pp. 176-177).

${ }^{42}$ Basilio indica questa prospettiva in termini positivi per l'organizzazione giornaliera dei monaci, quando scrive: «Che cosa ci può essere di più gioioso che imitare sulla terra il coro degli angeli? Subito, al principio del giorno, affrettarsi alla preghiera e celebrare con inni e cantici il Creatore; poi, quando il sole chiaramente risplende, mettersi al lavoro, mentre la preghiera ci accompagna in ogni luogo e condire il lavoro con inni, come con sale» [Epistulae 2,2, in BASILIO, Le lettere, Introduzione, testo criticamente riveduto, traduzione, commento a cura di M. Forlin Patrucco, I, Torino 1983 (Corona Patrum, 11), p. 64]. Ma il rifiuto del lavoro manuale, dovuto alle tendenze messaliane presenti nel movimento di Eustazio, non è infrequente, come si dice negli apoftegmi a proposito dell'abate Silvano che un giorno ricevette un monaco, il quale, alla vista dei fratelli al lavoro, gli disse: Non lavorate per il cibo che perisce (Gv 6,27). Maria ha scelto la parte migliore (Lc 10,42). Il santo asceta non rispose nulla, «ma chiamò un suo discepolo e gli disse: "Zaccaria, dà al fratello un libro e mettilo in una cella senza niente". All'ora del pranzo il monaco attese che qualcuno venisse a chiamarlo per il pasto, ma non vedendo nessuno domandò a Silvano: "Padre, non mangiano i fratelli oggi?". Alla risposta affermativa di Silvano, chiese perché non l'avessero chiamato e Silvano rispose: "Perché sei un uomo spirituale e non hai bisogno di questo cibo. Ma noi che siamo carnali dobbiamo mangiare e perciò lavoriamo. Tu invece hai scelto la parte buona, leggi tutto il giorno e non vuoi mangiare un cibo materiale". A queste parole, il monaco si prostrò e chiese perdono» (Vita e detti dei Padri, pp. 463-464).

${ }^{43}$ ATANASIO, Vita Antonii, cap. 3,6, p. 103.

${ }^{44}$ Basilio osserva che «alcuni si rifiutano di lavorare con il pretesto di pregare e recitare i salmi», ma vi è un tempo adatto per ogni cosa, «così mentre le mani si muovono nel lavoro, possiamo dar lode a Dio con la lingua, oppure con il cuore, con salmi, inni e cantici spirituali» (BASILIO, Le regole, pp. 178-179).

${ }^{45}$ Les sentences des Pères du désert. Nouveau recueil, ed. L. Regnault, Solesmes 1970, p. 239.

${ }^{46}$ Detti inediti, p. 171; CREMASCHI, I Padri del deserto, col. 374.

${ }^{47}$ BASILIO, Le regole, pp. 179-180.

${ }^{48}$ PALLADIO, La Storia Lausiaca, p. 11 (prologo); per il riferimento alla veglia notturna, S. PACHOMII Vita bohairice scripta, ed. L. Th. Lefort, Louvain 1953 (Corpus scriptorum christianorum orientalium, 89. Scriptores coptici, 7), p. 59, cap. 10-13.

49 BASILIO, Le regole, pp. 265-266 cap. 43.

${ }^{50}$ BASILIO, Le regole, p. 138, cap. 19,1; dove subito dopo, a proposito della temperanza alimentare, aggiunge: «Quanto ai cibi, poiché i bisogni di ciascuno sono diversi a seconda dell'età, del lavoro e della costituzione fisica, diversa è pure la misura e il modo di usarne. Ne deriva che è impossibile includere sotto una sola regola tutti quelli che cercano di vivere la vita cristiana, perciò, una volta fissata la misura per gli asceti che godono di buona salute, consentiamo a quelli cui è affidata la cura di governare la comunità di cambiare quella misura adattandola ai bisogni dei singoli». Sarà necessario perciò che chi è posto alla guida dei fratelli provveda «con un cibo particolare i malati o chi è affaticato da un duro lavoro o anche chi si prepara ad affrontare un lungo viaggio o qualche altra fatica, tenendo sempre conto dei bisogni di ciascuno. Non è dunque possibile stabilire un'identica regola per tutti riguardo all'orario dei pasti, al modo o alla misura in cui prendere il cibo, ma vi sia quale unico fine comune a tutti la soddisfazione dei bisogni» (ivi, pp. 138-139, cap. 19,1). Anche nella legislazione pacomiana, se da una parte è presente la preoccupazione che non vi siano disparità nella distribuzione del cibo, né che alcuno possa pretendere un trattamento particolare (Precetti 38; 41; 51; 74; Regolamenti 41; 50), dall'altra si mostra grande attenzione verso i fratelli malati o più deboli (Precetti 40; 42; 105; Regolamenti 24; 42). 


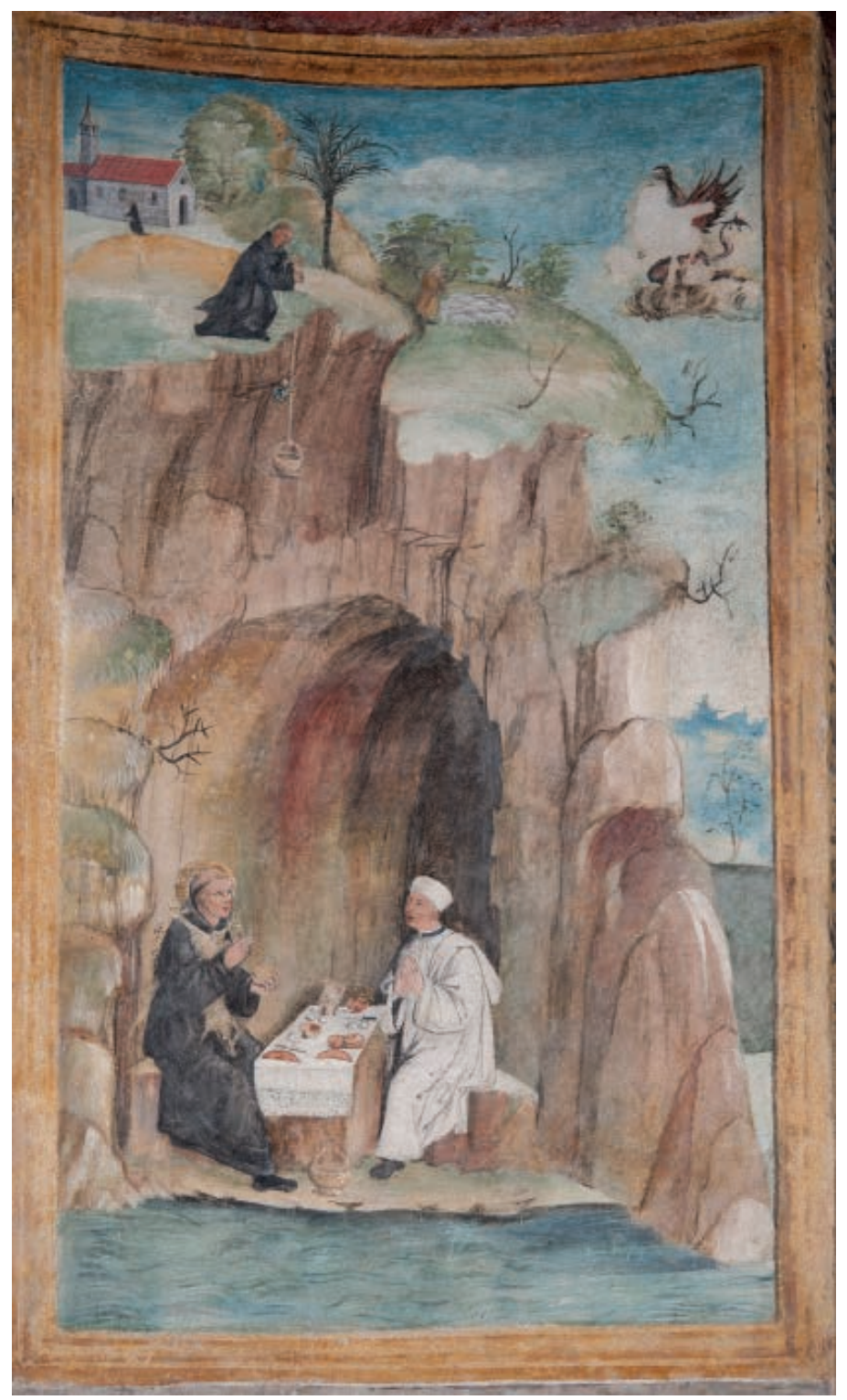

Fig. 15. Brescia, Santa Maria in Solario, affresco con scene di vita di san Benedetto, inizio XVI secolo

sul far della sera durante la settimana, benché in taluni casi l'accorrere dei fedeli alle celle dei padri li costringeva ad inoltrarsi nel deserto per salvaguardare la loro scelta di solitudine. L'ospitalità comunque era considerata sacra e non v'era timore di interrompere a qualsiasi ora del giorno il lavoro, la preghiera o la meditazione per accogliere un ospite (fig. 15). Diceva un anziano asceta ad un giovane che era venuto a cercarlo e che si scusava per il disturbo e per averlo costretto ad infrangere il suo proposito di vita: «Mia regola è accoglierti e rinviarti in pace ${ }^{5^{1}}$. Un concetto che continuerà ad essere caro a tutto il monachesimo successivo.

\section{SEPARATI DAL MONDO A MOTIVO DI DIO}

Se si sposta l'attenzione alle forme monastiche in Occidente, per la sua stessa ampiezza e precisione, di grande valore è la Regula Magistri che, nella prima metà del VI secolo, consente di seguire la vita claustrale quasi ora per ora, con una ricchezza di dettagli che raramente trova eguali nelle sillogi normative e consuetudinarie medievali ${ }^{52}$. Qui la porta del monastero andava tenuta sempre chiusa e al suo interno doveva trovarsi tutto il necessario alla vita dei monaci, per consentire loro di uscire il meno possibile, cosicché «chiusi dentro con il Signore» essi sarebbero stati «in qualche modo già nei cieli e separati dal mondo a motivo di Dio» (RM 95).

Lo sguardo può essere rivolto ad una comunità dell'Italia centrale dove l'esperienza di vita voluta dal Maestro aveva trovato il suo primo radicamento. Verso mezzanotte di un giorno invernale, i fratelli sono chiamati ad alzarsi per l'ufficio notturno e il compito di annunciare l'opera di Dio senza sbagli né ritardi spetta a due monaci detti "galli vigilanti” (RM 31,10); la liturgia termina prima dell'alba - la cui lunghezza, come quella degli altri uffici, variava anche di molto in quanto i salmi non sono tutti uguali e sono presi di seguito nel salterio - ed è separata dal Mattutino da un lungo intervallo, durante il quale si poteva tornare a dormire (RM 44,15-16). Al segnale convenuto ci si affrettava verso l'oratorio per celebrare il Mattutino: è l'aurora, a cui segue la recita dell'ora Prima quando ormai il sole è alto. Questa, come le altre piccole ore - Terza, Sesta e Nona -, è intercalata da pause di silenzio, da genuflessioni e inchini che hanno una precisa valenza religiosa e simbolica nella ritualità quotidiana (RM 40 e 47$)^{53}$.

Terminata Prima, si comincia il lavoro che è accompagnato dalla lettura: un tempo fondamentale per la preparazione dell'ufficio corale e della preghiera personale. La lectio, infatti, alla quale sono riservate tre ore al giorno, è fatta in comune a gruppi di dieci, sotto lo sguardo vigile dei «prepositi» ${ }^{54} \mathrm{e}$, mentre un fratello legge, gli altri ascoltano, cercando di memorizzare quanto hanno udito (RM 50,15). Il resto del tempo, vale a dire da sei a otto ore al giorno, si lavora manualmente nelle officine artigianali o, come nel caso dei fratelli meno dotati, in giardino ( $\mathrm{RM}$ 50); dalle loro attività restano esclusi i lavori agricoli fuori della clausura che non

\footnotetext{
${ }^{51}$ Detti inediti, p. 246; anche BASILIO, Le regole, cap. 45,1, p. 197 e n. 632; inoltre, CREMASCHI, I Padri del deserto, col. 376; EADEM, Introduzione, in BASILIO, Le regole, pp. 43-46; più in generale, F. THÉLAMON, Ascèse et sociabilité. Les conduites alimentaires des moines d'Égypte au IVe siècle, in Revue des études augustiniennes et patristiques, 38 (1992), pp. 295-321; G. ARCHETTI, Pellegrini e ospitalità nel medioevo. Dalla storiografia locale all'ospedale di Santa Giulia di Brescia, in Lungo le strade della fede. Pellegrini e pellegrinaggio nel Bresciano, Atti della Giornata di studio (Brescia, 16 dicembre 200o), a cura di G. Archetti, Brescia 2001 (Brixia sacra. Memorie storiche della diocesi di Brescia, VI, 3-4), pp. 69-128.

${ }^{52}$ Cfr. le puntuali note di sintesi di DE VOGÜÉ, Il primo monachesimo occidentale, coll. 376-385; per il testo della regola del Maestro, v. La Règle du Maître, cit.; inoltre, Regola del Maestro, I: Introduzione, traduzione e commento a cura di M. Bozzi; II: Introduzione, testo e note a cura di M. Bozzi e A. Grilli, Brescia 1965 .

53 Come in tutto il monachesimo antico, ogni salmo era seguito da una preghiera silenziosa (RM 29-49), ma la quantità di salmodia fissata dal Maestro era moderata, in conformità alle norme egiziane e orientali indicate dalle Institutiones di Cassiano; queste celebrazioni relativamente brevi, analoghe a quelle dell'Ufficio romano, differivano però considerevolmente dagli enormi uffici della tradizione della Gallia, ancora celebrati agli inizi del VI secolo a Lérins o ad Arles (cfr. DE VOGÜÉ, Il primo monachesimo occidentale, coll. 386 sgg., 390).

${ }^{54}$ L'esortazione del Maestro per i suoi monaci è quella di imparare a leggere e scrivere (RM 50, 13); con il termine praepositi (RM 11; RB 21 e 22; Ildemaro, pp. $323 \mathrm{sgg}$.), invece, sono indicati i due fratelli incaricati di vegliare su ogni gruppo di dieci monaci; essi non dovevano mai lasciare i fratelli affidati alla loro vigilanza per guidarli o riprenderli in ogni istante, di giorno e di notte, circa le disposizioni dell'abate e le norme disciplinari (DE VOGÜÉ, San Benedetto, pp. 100-102).
} 
competonoai monaci ma al personale rustico di servizio ( $R M$ 86,25-26). In Quaresima, a metà di ogni periodo di tre ore, si interrompe il lavoro e la lettura per fare un'orazione silenziosa tutti insieme. Questa osservanza quaresimale delle preghiere comunitaria «senza salmi» porta il Maestro a parlare della Quaresima, di cui regola lo svolgimento fino alla grande veglia pasquale (RM 51-53).

Celebrate Sesta e Nona - rispettivamente verso mezzogiorno e le quindici circa -, i fratelli si preparano a ricevere la comunione; la messa è celebrata solo la domenica e nella settimana i monaci prendono il pane consacrato, appositamente conservato, che santifica per contatto il vino non consacrato che essi bevono in memoria di quanto detto e fatto dal Signore ${ }^{55}$. Dopo il cibo spirituale, ci si reca in refettorio per assumere il cibo materiale, preparato per la cena - rispetto al giorno precedente infatti, in cui la comunità aveva pranzato a mezzogiorno e la sera aveva cenato, essendo un giorno di digiuno, si tratta dell'unico pasto -; poi c'è ancora un po' di tempo per il lavoro prima dei Vespri (o lucernario), la cui durata è simile a quella dell'ufficio del mattutino, e precedente l'accensione delle lampade per la sera. Prima del termine della giornata e di predisporsi per la notte, c'è spazio per un ultimo momento di fraternità in refettorio, preludio al silenzio notturno (fig. 16).

È ormai quasi il momento di Compieta, tutti ascoltano l'ultima raccomandazione dell'abate: «Su, o fratelli, affrettatevi in modo da terminare ogni cosa e non avere più occasione alcuna che ci costringa a parlare. È giunta l'ora, infatti, di affidarci al Signore e, una volta terminati gli uffici del giorno, all'avvicinarsi della notte, di chiudere a nostra volta la bocca per il riposo del silenzio e i nostri occhi per il sonno». Ancora per pochi minuti si danno degli ordini, segue Compieta e il lungo silenzio che non dovrà essere infranto per nessun motivo; gli ebdomadari hanno acceso la lampada che rischiarerà il dormitorio fino all'ora del Notturno, quando i vigilgalli sveglieranno l'abate sussurrando: «Signore apri le mie labbra, e la mia bocca annuncerà la tua lode», battendo i piedi leggermente finché il superiore non si sarà destato $(\mathrm{RM} 32)^{56}$.

\footnotetext{
55 Per l'uso settimanale della comunione e della liturgia eucaristica, v. DE VOGÜÉ, La Regola di san Benedetto, pp. 239-241; inoltre, G. ARCHETTI, "De mensura potus". Il vino dei monaci nel medioevo, in La civiltà del vino. Fonti, temi e produzioni vitivinicole dal Medioevo al Novecento, Atti della VII Biennale di Franciacorta (Monticelli Brusati - Antica Fratta, 5-6 ottobre 2001), a cura di G. Archetti, con la collaborazione di A. Baronio, R. Bellini e P. Villa, Brescia 2003, pp. 293-404.

${ }^{56} \mathrm{Il}$ compito di dare la sveglia ricadeva a turno sui fratelli di ciascuna decania, i quali controllavano l'orologio in coppia per paura che uno dei due si addormentasse, e quando giungeva l'ora andavano a svegliare l'abate in modo che tutto avvenisse secondo l'ordine indicato dalla Regola (La Règle du Maître, II, pp. 172-173, cap. 30,3-6).

57 CESARIO DI ARLES, Oevres monastiques, I. Oevres pour les moniales, edd. A. de Vogüé, J. Correau, Paris 1988 (SC 345), cap. 2,1-2. Per un rapido sguardo al monachesimo pre-benedettino in Gallia, cfr. G. MOYSE, Monachisme et réglementation monastique en Gaule avant Benoît d'Aniane, in Sous la Règle de saint Benoît. Structures monastiques et sociétés en France du Moyen Âge à l'époque moderne, Genève-Paris 1982 (Hautes études médiévales et modernes, 5), pp. 3-19.

${ }^{8}$ CESARIO DI ARLES, Oevres monastiques, cap. 22,1-2, e 66,1; anche 18,3-5; 20,2-3; 21,7; 66-70.

59 CESARIO DI ARLES, Oevres monastiques, cap. 66,1; per uno sguardo generale cfr. Lérins, une île sainte de l'antiquité au moyen-âge, ed. Y. Codou, M. Lauwers, Turnhout 2009 (Collection d'études médiévales de Nice, 5).
}

${ }^{60}$ CESARIO DI ARLES, Oevres monastiques, cap. 15,1-2. 
Duro era anche il regime di vita nei monasteri colombaniani, segnato da digiuni, lavoro e un pesante carico liturgico e salmodico ${ }^{61}$. Dopo il Mattutino, che a volte poteva comprendere la metà del Salterio, soprattutto presso le monache, appare importante la Seconda ora perché segnava la fine del lungo silenzio della notte, accompagnata poco dopo dalla celebrazione di Terza. Questi e gli altri uffici minori del giorno consistevano sempre di tre salmi e da sei versetti di intercessione nei quali si esprimevano le intenzioni permanenti della preghiera dei monaci: il perdono dei peccati, la salvezza del popolo cristiano, i diversi gradi del sacerdozio, $i$ benefattori, la pace tra i re, infine i persecutori e i detrattori del monastero. Tra un ufficio e l'altro si poneva l'attività lavorativa, che iniziava e terminava con una preghiera, e che ciascun fratello svolgeva in base all'obbedienza specifica; alla fine del lavoro si procedeva alla confessione privata delle colpe davanti al superiore, alla penitenza per gli errori privazione di qualcosa, battiture corporali, genuflessioni o recita di salmi - e al pasto in refettorio.

Finito di mangiare, si raccoglievano le briciole avanzate e si pregava. Giunto il crepuscolo venivano accese le lampade, non prima di averle benedette, compito che spettava al fratello più anziano, mentre il grande ufficio dell'«inizio della notte», chiamato Dodicesima ora (duodecima) perché come quello di mezzanotte consisteva di dodici salmi, precedeva il momento di andare a letto. Si trattava di una liturgia di pace che introduceva il silenzio notturno e serviva a riconciliarsi con Dio e con i fratelli prima di sprofondare nel sonno, simbolo e prefigurazione del riposo eterno della morte. E appunto in previsione di quest'ultimo, che per qualcuno sarebbe potuto arrivare in quella notte stessa, si recitavano le preghiere dei morenti: il Padre nostro e il Credo. Poi tutto taceva fino al segnale del Notturno.

\section{“ORA ET LABORA” NELLA TRADIZIONE BENEDETTINA}

Se la Regola del Maestro divideva l'anno in due grandi periodi, l'inverno e l'estate - che cominciavano l'uno con l'equinozio d'autunno ( 24 settembre) e l'altro con la Pasqua ${ }^{62}$ - la Regola benedettina presenta un'articolazione più complessa che tiene conto delle diverse occupazioni monastiche e si modula in funzione di queste nel corso delle stagioni ${ }^{63}$.
Anche per l'abate cassinese la festa di Pasqua fissa l'inizio del periodo estivo, ma non altrettanto avviene per l'orario invernale del digiuno ( 13 settembre), del lavoro ( $1^{\circ}$ ottobre) e della preghiera vigilare $\left(1^{\circ} \text { novembre }\right)^{64}$, mentre le stagioni dell'anno si suddividono in estate, inverno e quaresima. Benedetto assume una posizione autonoma rispetto al Maestro anche riguardo ai giorni della settimana, durante i quali si digiuna il mercoledì e il venerdì (RB 41,2; RM 28) - quando è previsto un solo pasto a nona, mentre negli altri si pranza a mezzogiorno e si cena dopo il vespro -, come pure circa le ore della giornata.

Nell'antichità e nel medioevo le ore erano la dodicesima parte del giorno e della notte, per cui la loro durata mutava a seconda delle stagioni - d'estate le giornate erano più lunghe della notte ed erano più corte d'inverno - rendendo complicato il loro computo. Se il Maestro aveva adottato come riferimento la celebrazione delle ore di Terza, Sesta e Nona, per Benedetto questi uffici liturgici non sono fissi ma potevano oscillare durante l'anno, anche in modo significativo, perché erano in funzione delle occupazioni dei fratelli ${ }^{65}$. Ciò però doveva avvenire «con una ragionevole discretione» secondo il commento che ne dà il monaco Ildemaro ${ }^{66}$ - per permettere di adattare ai tempi del lavoro e della lettura la celebrazione dell'opus Dei; in questa maniera l'orario dell'ufficio divino, anziché delimitare lo spazio temporale destinato a tali occupazioni, si modulava in base alla loro variabilità annuale, alla durata delle giornate e ai bisogni della comunità (figg. 17, 18).

I capitoli della Regola in cui vi sono indicazioni sull'orario dei monaci sono numerosi e toccano i diversi aspetti della vita; tra questi si possono ricordare almeno l'VIII, dedicato agli "uffici divini nella notte", il XVI su "come celebrare l'opera di Dio durante il giorno", il XLI riguardante le ore in cui i fratelli debbono prendere i pasti e il XLVIII sul lavoro manuale e la lettura. È all'abate innanzitutto, o a un fratello «assai diligente» designato dal superiore, che spetta il compito di dare la sveglia ${ }^{67} \mathrm{e}$ indicare l'ora per gli impegni comuni (RB 47,1), a partire dal segnale della preghiera, che comincia molto presto - «nel cuore della notte mi alzo a renderti grazie» (Sal 118,62; RB 16,4) - con l'ufficio di Veglia o Notturno (più tardi detto Mattutino): «ci si alza all'ora ottava della notte, in modo da poter dormire un po' più della metà

${ }^{{ }_{11}}$ SAN COLOMBANO, Règles et Pénitentiels monastiques, ed. A. de Vogüé, Bellefontaine 1989 (Vie monastique, 20), pp. 22-23; per i testi: Regula Columbani, in Dizionario degli istituti di perfezione, VII, Roma 1983, coll. 1607-1615; Regula Columbani ad virgines, ivi, coll. 1566-1569; Regula cuiusdam Patris ad monachos, ivi, coll. 1571-1573; Regula Waldeberti, ivi, coll. 1602-1603; Regula Donati, ivi, coll. 1574-1575; inoltre, A. LUCIONI, Monachesimo occidentale e monaci missionari, in Storia del monachesimo, II. L'età medievale (secoli VIII-XV), a cura di M. Benedetti, direzione scientifica di E. Prinzivalli, Roma 2015, pp. 61-84; G. ARCHETTI, Da Bangor a Bobbio: il monachesimo tra VI e VII secolo, in Teodolinda. I longobardi all'alba dell'Europa, Secondo convegno internazionale (Monza, Gazzada Schianno, Castelseprio-Torba, Cairate, 2-7 dicembre 2015), a cura di G. Archetti, Spoleto 2017 (Centro studi longobardi. Convegni, 2), in corso di stampa.

${ }^{62}$ La Règle du Maître, I, pp. 36-37, con riferimento a RM 28,33-34-50.

${ }^{63}$ Uno dei tratti rilevanti dell'orario benedettino è la sua complessità; al posto di basare semplicemente l'impiego del tempo sulle grandi articolazioni del giorno civile ed ecclesiastico - Terza, Sesta e Nona - come facevano gli antichi monaci e il Maestro, l'abate cassinese «anticipa o ritarda parecchie volte queste ore dell'ufficio per dare alla lettura e al lavoro la durata variabile che giudica opportuna. Questa preoccupazione del tempo opportuno per ogni cosa comporta una certa relativizzazione dell'ufficio divino, il cui orario, invece di delimitare le occupazioni, si adatta alle necessità di queste ultime» (DE VOGÜÉ, San Benedetto, p. 121).

${ }^{64}$ Cfr. rispettivamente RB 41,6; 48,10; e 10,1; sull'organizzazione dell'orario annuale si veda il commento di Ildemaro, pp. 276-278; ARCHETTI, "Nihil operi Dei praeponatur", pp. 71-79; inoltre, PICASSO, Il monaco e il tempo, pp. 41-42.

${ }_{6}$ «Per Benedetto - scrive padre Picasso - l'ora Terza è celebrata alla seconda ora durante l'inverno e alla quarta ora durante l'estate; Sesta a volte è detta ad ora intermedia non meglio precisata, altra volta è passata sotto silenzio; Nona è anticipata a metà dell'ora ottava durante l'estate, ritardata fino all'ora decima, o forse omessa, durante la Quaresima» (PICASSO, Il monaco e il tempo, pp. 43-44; per i riferimenti alla RB si veda il cap. 48, dedicato al lavoro manuale, i § 10.3.4-5.11).

${ }^{66}$ Ildemaro, pp. 276, anche 307-308.

${ }_{77}^{67}$ Ildemaro, p. 475, a commento di RB 47: Il segnale per l'ufficio divino. 


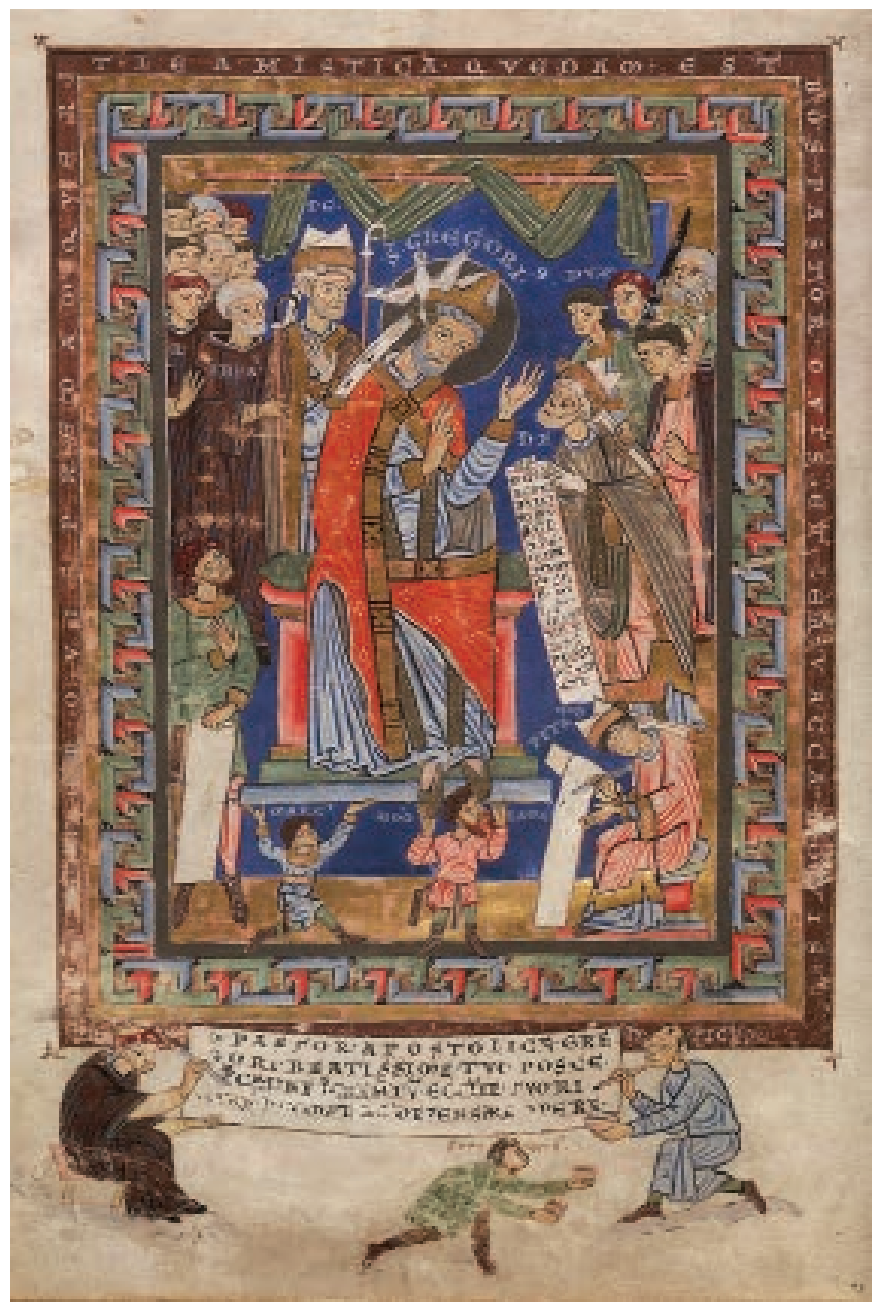

Fig. 17. Stockholm, National Library of Sweden, ms A 144, Olomouc Collectarium, Gregorio Magno circondato da dignitari, chierici e monaci, 1142 circa

della notte stessa e levarsi ormai riposati», recita la Regola (RB 8,1-2), cioè aver recuperato le forze per l'ufficio divino nella forma migliore ${ }^{68}$.

Le Lodi erano cantate alle prime luci dell'alba; poi, a intervalli relativamente brevi seguivano gli uffici del giorno, alla Prima, Terza, Sesta e Nona ora, che si chiudevano a sera col Vespro secondo l'invito del profeta: Sette volte al giorno io ti lodo (Sal 118,164; RB 16,1.3) ) $^{69}$ e la recita di Compieta che poneva fine alla giornata, introducendo i monaci alla taciturnitas notturna (RB 42,8-9) $)^{70}$. Ildemaro illustra con precisione il tempo che separava il pasto serale dall'ufficio di

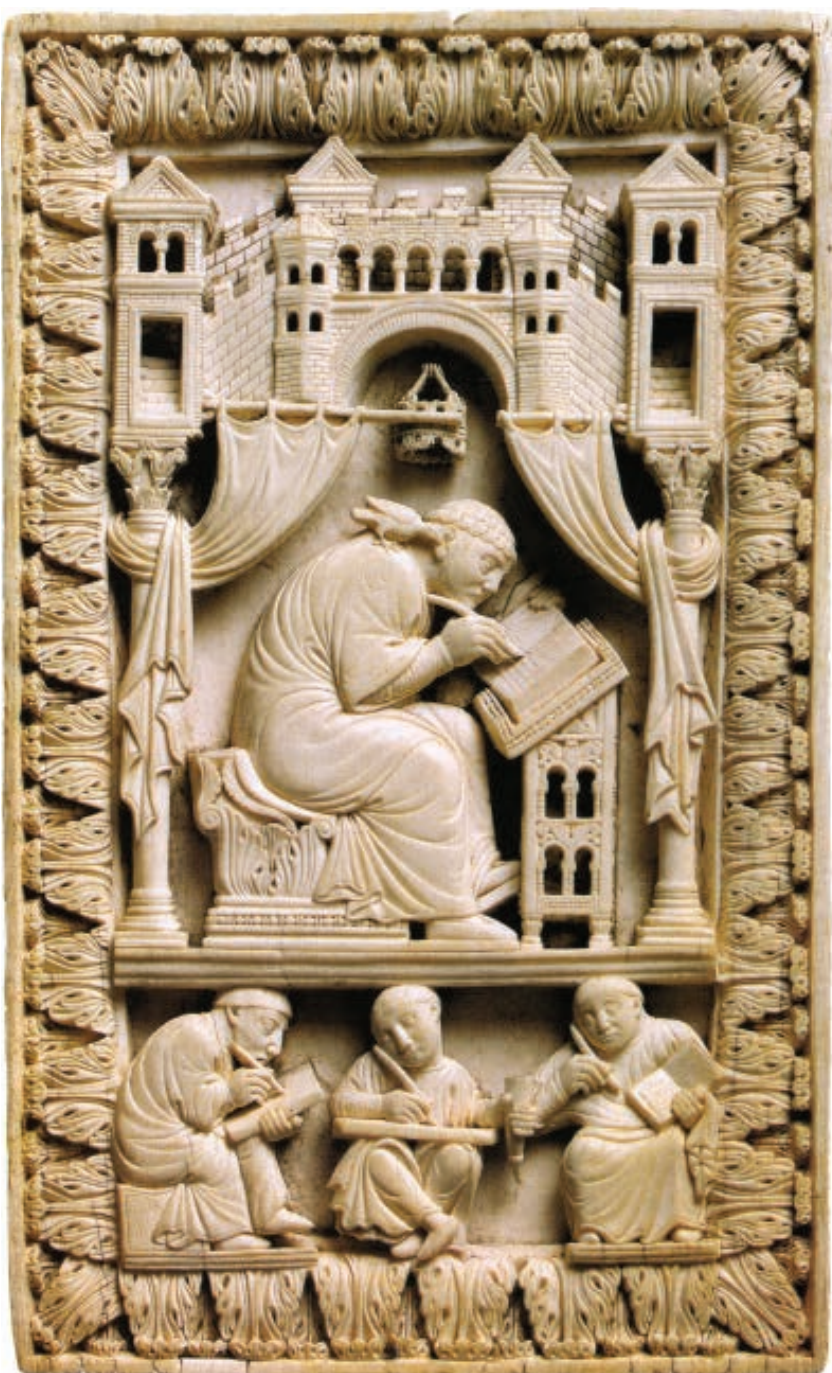

Fig. 18. Vienna, Kunsthistorisches Museum, rilegatura in avorio con san Gregorio e tre copisti, 850-875 circa

Compieta: «[i monaci] si alzino da cena trascorso un brevissimo intervallo, per consentire agli inservienti di mangiare, e subito si apprestino ad ascoltare le Conferenze spirituali» di Cassiano ${ }^{71}$ (RB 42,3); «se invece si è cenato più tardi del solito si passi immediatamente alla lettura delle Conlationes, durante la quale nessuno deve parlare tranne il lettore incaricato o l'abate che ne spiega il contenuto; inoltre, mentre i fratelli lavano i piedi non si deve cantare né leggere, nel senso che prima si fanno le abluzioni ai piedi e solo dopo si leggono le Conferenze spirituali» ${ }^{72}$.

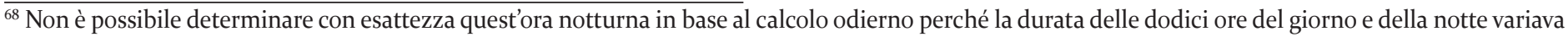
a seconda delle stagioni; infatti, i periodi di buio e di luce erano divisi in dodici ore di uguale ampiezza, per cui durante l'inverno le ore della notte, pur essendo uguali tra loro, risultavano più lunghe dei sessanta minuti odierni, e di conseguenza più corte quelle del giorno che invece si allungavano, superando quelle notturne, durante l'estate (Ildemaro, pp. 276-277). Si può tuttavia dire, almeno indicativamente, che i monaci si alzavano verso le due del mattino d'inverno, cioè dopo aver dormito sette-otto ore, mentre d'estate - dovendo le lodi essere recitate allo spuntar della luce, ossia verso le cinque, e durando gli uffici notturni circa un'ora e mezza - la levata avveniva dopo le tre (cfr. l’ampio commento in La Règle de saint Benoît, V, pp. 593-594 sgg.). Nella RM, invece, le vigilie erano regolate dal canto del gallo (pullorum cantus) e dovevano essere celebrate prima che cantasse in inverno e poco dopo in estate (RM 33,4 ). ${ }^{69}$ Cfr. pure il commento di Ildemaro, pp. 306-308. Pier Damiani nella lettera al nobile ravennate Tegrimo, dopo averlo esortato alla preghiera personale, lo istruisce sul significato mistico della liturgia delle ore e gli mostra la differenza tra l'ufficio monastico e quello dei chierici; quindi spiega che «le ore di cui parl[a] sono: le lodi mattutine (che dobbiamo iniziare tra l'alba e l'aurora), cui seguono Prima, Terza, Sesta, Nona, Vespro e Compieta»; poi indica le ragioni che, a suo avviso, avevano portato all'aumento salmodico in età carolingia: «Nelle Gallie [...] i devoti padri dei cenobi vedendo che la maggior parte dei fratelli eccedeva nella misura della refezione che ci è stata trasmessa dal santo padre Benedetto e che non potevano contenersi dentro il limite prescritto per ogni giorno dalla Regola, ritennero opportuno, ordinando gli uffici di ciascuna ora, aggiungere anche altri salmi, sì che quella trasgressione di una misura più abbondante di cibo potesse essere compensata con l'aumento dei salmi» [PIER DAMIANI, Lettere, epist. 17, cap. 4.10, pp. 311, 319.321]. ${ }^{70}$ Sul concetto di taciturnitas o "amore per il silenzio" in san Benedetto, cfr. C. BONETTI, Dalla "taciturnitas" alle relazioni sociali e al colloquio con Dio nella "Regula Benedicti", in Benedictina, XXXVIII, 2 (1991), pp. 307-349.

${ }^{71}$ Ildemaro, p. 454; si tratta delle Conlationes Patrum del monaco Giovanni Cassiano († 435).

${ }^{2}$ Ildemaro, p. 454 .
} 
L'ufficio della notte era il più lungo ed elaborato (RB 8-10); era suddiviso in diverse parti, chiamate Notturni, ognuna delle quali consisteva di sei salmi e quattro lezioni tratte dalla Bibbia e dagli scritti patristici, con responsori o versetti di meditazione, che si riferivano all'argomento delle letture. Di domenica e nei giorni festivi l'ufficio della notte comprendeva tre Notturni e richiedeva più di due ore per essere recitato, per questo bisognava alzarsi un po' prima degli altri giorni (RB 11-12;14). L'impegno settimanale prevedeva comunque che i fratelli recitassero «tutto il Salterio, con i suoi 150 salmi, e di ricominciarlo dall'inizio ogni domenica all'ufficio delle Vigilie» (RB 18,23).

Terminati i Notturni, la comunità non tornava a letto come permetteva il Maestro ${ }^{73}$; c'era infatti solo un breve intervallo prima dell'aurora, quando veniva cantato l'ufficio delle Lodi ( $\mathrm{RB}$ 13), mentre al sorgere del sole seguiva la recita dell'ufficio di Prima (RB 16). I monaci si recavano quindi alle loro occupazioni - lavoro e lettura principalmente -, che variavano secondo le stagioni ed erano stabilite nella riunione mattutina del capitolo, sempre intervallate però dalla periodicità della preghiera comunitaria in coro, durante la quale l'atteggiamento interiore e la mente dovevano essere un tutt'uno con il tenore del canto e l'intonazione della voce (RB 19,7).

Il segnale orario delle diverse occupazioni della giornata - preghiera, lavoro, lettura, cibo, sonno - era dato con precisione dai rintocchi della campana, dal suono della tabula o di campanelle; si trattava di un compito importante affidato a fratelli responsabili, di solito due, e non erano tollerati errori o sbagli dovuti a pigrizia. Nell'alto medioevo, secondo la testimonianza di Ildemaro, i monaci facevano uso di un orologio ad acqua per dare la sveglia e suonare la campana al momento giusto, anche se la precisione di tali strumenti non era del tutto affidabile ${ }^{74}$; per questo in alcuni codici monastici si consiglia l'osservazione astronomica per controllare l'orario notturno, pur con i limiti della variabilità atmosferica, mentre frequenti sono i casi - come prescrive il Maestro (RM 31;33; 49) - in cui un fratello doveva vegliare per controllare l'orologio, al fine di dare il segnale al momento opportuno ${ }^{75}$. Poteva accadere in effetti che l'incaricato non si svegliasse in tempo per suonare la campanella all'orario stabilito; la Regola benedettina stigmatizza la negligenza di quel fratello, ma si preoccupa soprattutto di far riprendere quanto prima alla comunità l'orario normale, abbreviando se necessario la durata della preghiera $(\mathrm{RB} 11,11)^{76}$.

\section{ALCUNE ANNOTAZIONI DAL COMMENTO DI ILDEMARO}

Nell'esposizione del monaco Ildemaro della normativa cassinese si ricavano varie osservazioni sulla prassi claustrale in età carolingia di cui dare conto. A proposito dei diversi offcia monastici il maestro di Corbie osserva che san Benedetto «ha fatto bene a distinguere gli uffici divini dal momento che ne esistono altri» $7^{7}$, e spiega che l'ufficio vespertinum «viene detto così dalla stella del vespro che sorge la sera in oriente; [...] gallicinium invece è quando i galli si mettono a cantare e il loro canto preannuncia la luce; mentre matutinum è posto tra la fine delle tenebre e l'arrivo dell'aurora, essendo il tempo che dà inizio al mattino», annunciato dalla stella Lucifero «che sorge all'inizio del mattino $»^{78}$. Rispetto al fatto che i fratelli si levano «all'ora ottava della notte» $(\mathrm{RB} 8,1)$, cioè verso le due del mattino d'inverno o le tre e mezza d'estate, Ildemaro si chiede a quale parte della notte corrisponda e illustra con un disegno l'orologio notturno, grazie al quale mostra la successione delle ore con il loro inizio, la durata e la fine, precisando che per rispettare con regolarità tale successione temporale «bisogna usare un orologio ad acqua»79.

Spiega quindi il significato della loro levata notturna per la preghiera in base a nozioni di carattere fisiologico, in quanto questo permetteva ai monaci di alzarsi per la vigilia «ormai riposati» $(\mathrm{RB} 8,2)$ un po' dopo la metà della notte. Il termine digesti, infatti, riguarda i cibi e la loro digestione, mentre l'espressione «per decoctionem ciborum - osserva si riferisce all'assunzione di un sufficiente periodo di sonno poiché tanto più l'uomo non si riposa nel sonno, tanto meno assimila consumandoli gli alimenti. Invero il cibo si digerisce soprattutto dormendo durante il sonno, e la digestione non è completa prima della metà della notte» ${ }^{80}$. Un congruo periodo di riposo, nota da parte sua il Maestro (RM 33,19-30), serviva per assimilare gli alimenti dando ai fratelli l'energia fisica per affrontare con prontezza e fervore la preghiera notturna.

All'infuori delle ore della liturgia comunitaria la Regula Benedicti suddivide la giornata del monaco tra il lavoro manuale e il tempo della lettura: «perciò i fratelli in determinate ore devono essere occupati in lavori manuali, in altre nella lettura divina» ${ }^{8_{1}}$. Ildemaro annota che durante

\footnotetext{
73 «Il tempo che rimane dopo le vigilie - cioè dopo l'ufficio notturno, recita RB 8,3 - venga impiegato dai fratelli che ne hanno bisogno nello studio del salterio o della sacra scrittura»; in questo modo Benedetto ha eliminato il cosiddetto "secondo sonno" previsto dal Maestro (RM 33,9.16-18) e assai diffuso nel monachesimo antico, che consentiva ai monaci di tornare a letto tra gli uffici notturni e le Lodi d'inverno e, tra le Lodi e l'ufficio di Prima in estate.

${ }^{74}$ Ildemaro, pp. 277-278, v. anche 287-289, 307-308, 488; ARCHETTI, “Nihil operi Dei praeponatur", pp. 71-79.

75 Ildemaro, p. 475; per il riferimento a meridiane e clessidre cfr. le note di A. CALMET, Commentario letterale, istorico e morale sopra la Regola di S. Benedetto con alcune osservazioni sopra gli Ordini Religiosi che seguitano la stessa Regola, II, in Arezzo 1751, pp. 95-96.

${ }^{76}$ Ildemaro, pp. 287-289.

77 Ildemaro, p. 270.

${ }^{78}$ Ildemaro, pp. 270-271.

79 Ildemaro, pp. 277-278, v. anche 307-308, 488; in RM 56,21 si parla invece di horelogium, termine con cui si indica verosimilmente una meridiana poiché si fa riferimento a come il sole disegna le ore del giorno.

${ }^{80}$ Ildemaro, pp. 278-279; per questi aspetti G. ARCHETTI, “Mensura victus constituere". Il cibo dei monaci tra Oriente ed Occidente, in L'alimentazione nell'alto medioevo: pratiche, simboli, ideologie, Sessantatreesima settimana di studio (Spoleto, 9-14 aprile 2015), Spoleto 2016, pp. 771-772.

${ }^{81}$ Cfr. RB 48,1 e di seguito: «da Pasqua all'inizio di ottobre, al mattino, usciti da Prima, i fratelli si occupino dei lavori necessari fin verso l'ora quarta; dall'ora quarta fin verso l'ora in cui celebreranno Sesta, si dedichino alla lettura. Finita Sesta e terminato di pranzare, riposino sul loro letto in assoluto silenzio; se qualcuno vuole leggere per conto suo, lo faccia pure, ma in modo da non disturbare nessuno. Si reciti nona con un po' di anticipo, a metà dell'ora ottava, e fino al Vespro ci si dedichi nuovamente alla lettura [...]. Dall'inizio di ottobre al principio della Quaresima ci si dedichi alla lettura sino alla fine dell'ora seconda; alla seconda ora si reciti Terza, e poi fino a nona tutti attendano al lavoro che è stato loro assegnato. Al primo segnale di nona ciascuno interrompa il lavoro e si tenga pronto per il suono del secondo segnale. Terminato il pranzo, si dedichino a letture personali o allo studio dei salmi. Nei giorni di Quaresima leggano dalla mattina fino all'ora terza compresa, poi lavorino sino alla fine dell'ora decima. In questi giorni ognuno riceva un libro
} 


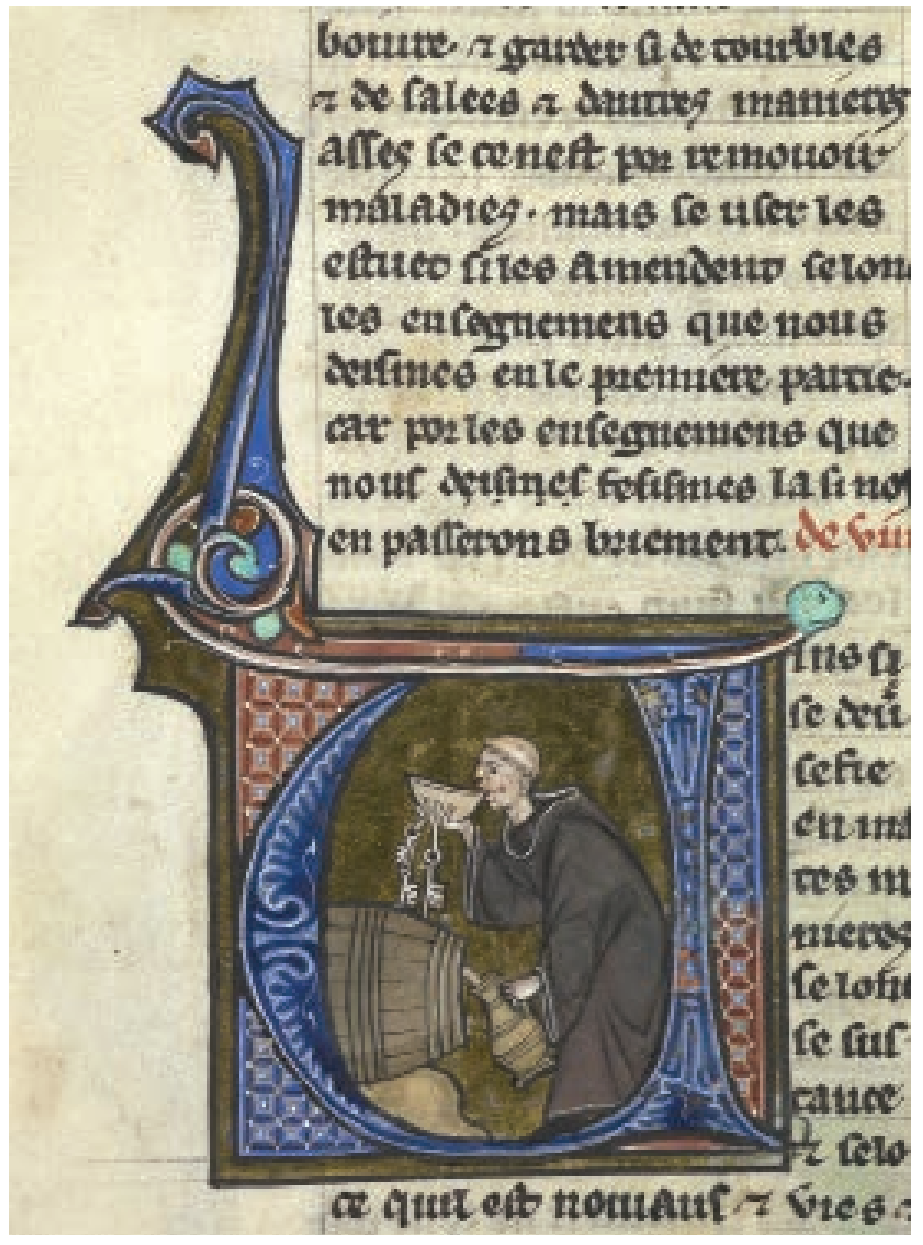

Fig. 19. London, British Library, Sloane ms 2435, f. 44v, Cellerarius che assaggia il vino da una botte, fine XIII secolo

la lettura due monaci anziani vigilavano che i fratelli non si perdessero in chiacchiere, né sciupassero il loro tempo, ma si applicassero con impegno nel rispetto del silenzio, mentre i fanciulli erano seguiti dai loro educatori ${ }^{82}$. E precisa che coloro che erano sotto custodia, cioè i pueri oblati, «leggevano insieme con i loro maestri» nella scuola, esercitandosi sulle tavolette di cera ${ }^{8}$; gli altri fratelli dovevano invece stare nei chiostri per conto proprio e non da soli nelle stanze o nel dormitorio: così avrebbero potuto «provare, se possibile, la contemplazione o le lacrime». Se tuttavia vi era «la necessità di mettere in quel luogo un fratello saggio», a cui i monaci potevano ripetere o leggere la loro lettura se ne avevano bisogno, si poteva farlo, senza però che ciò andasse a detrimento del raccoglimento degli altri ${ }^{84}$.

L'insistenza benedettina sul lavoro, essendo l'otiositas nemica dell'anima ( $R B 48,1)$, è un dato proveniente dalla

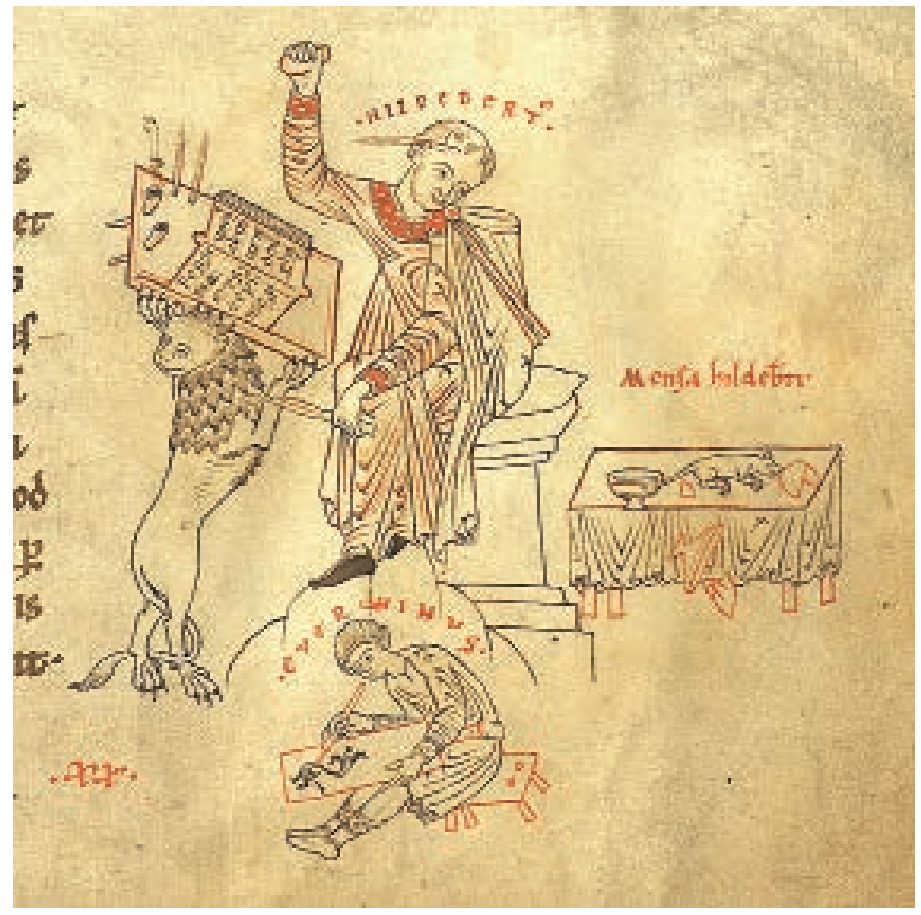

Fig. 20. Prague, Capitular Library, ms A XXI/1, c. 133r, Agostino, De civitate Dei, Hildebertus miniatore con l'aiutante Everwinus, 1140 circa

tradizione orientale e rispondeva ad una funzione pratica e ascetica insieme, perché sovveniva ai bisogni materiali della comunità, consentendo ai monaci di esercitare la carità e crescere in umiltà, oltre a rappresentare una forma di mortificazione in contrasto con l'otium della cultura antica. I fratelli artigiani dovevano esercitare il loro mestiere a discrezione dell'abate e il prodotto della loro fatica poteva essere venduto senza intenti speculativi ( $\mathrm{RB}$ 57); gli altri andavano a lavorare nei campi e nell'orto del monastero, si occupavano di attività gestionali e delle incombenze domestiche, delle pulizie, della lavanderia e della cucina.

Il bilanciato equilibrio benedettino tra lavoro manuale e studio cominciò tuttavia presto ad incrinarsi e, già nella tarda età longobarda, il lavoro, inteso come fatica fisica e impegno manuale, divenne semplicemente un momento formale della ritualità quotidiana ${ }^{85}$ (figg. 19, 20). Ciò portò ad anticipare taluni uffici e a ridurre il tempo destinato alle diverse occupazioni per il funzionamento del cenobio affidate per lo più a personale ausiliario e servile -, mentre il lavoro manuale consisteva ormai soltanto nel togliere le erbe ai legumi, pulire il refettorio, capare le verdure e preparare gli alimenti necessari in cucina all'alimentazione claustrale $^{86}$. Il valore simbolico aveva preso il sopravvento su quello dell'impegno e della fatica fisica.

dalla biblioteca, e lo legga tutto di seguito e per intero. Questi libri dovranno essere distribuiti all'inizio della Quaresima» (RB 48,3-6.10-16; e il commento articolato di Ildemaro, pp. 481-483, 487).

${ }^{82}$ Ildemaro, pp. 482-483.

${ }_{83}$ Ildemaro, p. 481; per questi aspetti G. ARCHETTI, L'educazione dei «pueri oblati»: reclutamento, formazione e finalità, in La historiografia medieval davant la crisi. La historiografía medieval ante la crisis, ed. M. Elisa Varela-Rodríguez, Documenta Universitaria, Girona 2015 (Estudis de Cultura Escrita i Visual, 3), pp. 67-124; IDEM, «Sub virga magistri». Custodia e disciplina nell'educazione carolingia dei pueri oblati, in Studi medievali, terza serie, LVII, 2 (2016), pp. 527-582.

${ }^{8}$ Ildemaro, pp. 481, 483.

${ }^{85}$ LAWRENCE, Il monachesimo medievale, p. 157.

${ }^{86}$ Così Ildemaro, pp. 486-487, ma anche le consuetudini di Cluny dell'XI secolo: «il lavoro non consiste in nient'altro che sgusciare i fagioli nuovi o sradicare le erbacce che soffocano le piante buone nell'orto e, a volte, nel preparare le pagnotte per il forno. Nei giorni in cui deve essere compiuto, dopo aver tenuto un capitolo più breve del solito, l'abate dice: Adesso passiamo al lavoro manuale. Allora tutti i fratelli escono in processione, con i ragazzi in testa, verso l'orto» (UDALRICUS, Antiquiores consuetudines Cluniacensis monasterii, in Patrologia latina, 149, coll. 675-677); è nell'orto infatti, precisa Ildemaro, che «nasce sempre qualcosa» e a differenza dei campi coltivati, che «producono frutti una sola volta all'anno», i monaci non restano «mai senza prodotti» 
Rispetto al capitolo sul lavoro manuale, Ildemaro precisa però che esso "condensa la magna pars della Regola»" mentre nella dialettica tra vita attiva e vita contemplativa, esemplificate dalle figure bibliche di Lia e Rachele, nota che la prima è presupposto della seconda e il monaco «non può giungere alla contemplazione senza essersi prima esercitato nella vita attiva»; il fratello, infatti, che «in modo graduale e corretto eserciterà i compiti manuali, quando si dedicherà alla lettura riceverà la contemplazione o le lacrime. Mai invero si potrà applicare alla lettura fruttuosamente se prima non avrà esercitato in modo giusto i doveri manuali. La vita contemplativa è la lettura, la preghiera e il canto dei salmi; la vita attiva è la pratica manuale» ${ }^{88}$, ma le due attività sono strettamente connesse e necessarie al cammino di perfezione.

Quando poi si dice che i fratelli devono lavorare sino all'ora decima (RB 48,14), osserva ancora il commentatore franco, ciò è corretto perché al tempo di san Benedetto «in monastero non veniva celebrata la messa; ora, invece che la messa è cantata, i fratelli non possono lavorare fino al termine dell'ora decima e poi dire la messa, facendo tutto con la luce del giorno, per questo l'abate deve considerare che $\mathrm{i}$ monaci lavorino fino a quel tempo che consente poi a loro di dire la messa, il Vespro e di cenare, facendo ogni cosa con la luce naturale. Di conseguenza, il lavoro non deve prostrarsi sino al termine dell'ora decima, ma all'inizio dell'ora decima essi devono cantare Nona e, trascorso un breve intervallo, passare subito al Vespro ${ }^{89}$. In questo è confermata la prassi benedettina di svolgere tutte le attività, compresi i Vespri e la cena, con la luce diurna per contenere il più possibile ogni risorsa in un tempo di penuria come quello della guerra greco-gotica.

Per altro verso, la giornata del monaco, benché iniziasse alle prime ore del mattino, non era eccessivamente ampia in quanto la comunità si ritirava al crepuscolo e, anche le più lunghe giornate estive, erano inframezzate da un riposo pomeridiano ${ }^{90}$. Al mattino, dopo aver detto l'ufficio di Prima, seguiva un intervallo di circa due ore, durante il quale i fratelli si mettevano le scarpe, si lavavano mani e faccia al lavabo situato nel chiostro e si dedicavano alla lettura o a piccoli servizi domestici prima di tornare in chiesa, verso le nove, per l'ufficio di Terza. Usciti dal coro, la riunione più importante era il capitolo che si teneva al mattino, dove si recavano in processione e, dopo essere entrati nella sala capitolare, sedevano al loro posto negli stalli collocati lungo le pareti ${ }^{91}$. L'assemblea era presieduta dall'abate, o dal priore, che spiegava la lettura e i passi della Regola, oggetto di esame quel giorno, con un sermone; poi affidava a ciascuno il suo compito quotidiano e apriva la discussione sui problemi della comunità o sulle questioni che riguardavano il monastero.

Era questo il momento in cui coloro che avevano commesso infrazioni confessavano le loro colpe ( $\mathrm{RB} 23$ ) e ricevevano la punizione per quanto commesso. Per esempio, al segnale dell'ufficio divino o al suono della campana tutti dovevano affrettarsi e lasciare quanto stavano facendo: ogni ritardo senza motivo veniva punito (RB 43); Ildemaro precisa che «chi arriva tardi se sta davanti o in un posto più elevato, deve andare all'ultimo posto, se invece sta in fondo o in mezzo, deve stare in disparte», e aggiunge che nel «suo monastero» e in quelli transalpini vi era la consuetudine che i ritardatari stessero separati dal resto della comunità ${ }^{22}$. Se invece uno giungeva in ritardo a mensa, oltre a mangiare in disparte rispetto agli altri, era anche privato dalla sua razione giornaliera di vino $(\mathrm{RB} 43,16)^{93}$. Terminato il capitolo verso metà mattina, seguiva un periodo di tempo destinato al lavoro o allo studio fino a mezzogiorno, quando il suono della campana chiamava tutti all'ufficio di Sesta.

L'ora del pranzo (RB 41), che era il pasto principale, variava a seconda della stagione (fig. 21): a partire dalla Pasqua era consumato subito dopo mezzogiorno al termine della messa solenne, mentre la cena si faceva dopo i Vespri; nei giorni più brevi dell'inverno invece, in Avvento e Quaresima, i fratelli prendevano un solo pasto a metà pomeriggio, anche se era loro consentito ricevere la caritas, ossia uno spuntino a base di pane e vino, prima di Compieta e in altri momenti della giornata $^{94}$. I pasti, come ogni altra attività, avevano il loro

(Ildemaro, p. 608); inoltre G. ARCHETTI, Scuola, lavoro e impegno pastorale: l'abbazia di Leno nel medioevo (secoli IX-XIV), in L'abbazia di S. Benedetto di Leno. Mille anni nel cuore della pianura Padana, Atti della giornata di studio (Leno, Villa Seccamani, 26 maggio 2001), a cura di A. Baronio, Brescia 2002 (Brixia sacra. Memorie storiche della diocesi di Brescia, VII, 1-2), pp. 97-101.

${ }^{87}$ Ildemaro, p. 479 .

${ }^{88}$ Ildemaro, pp. 478-479.

${ }^{89}$ Ildemaro, p. 481.

90 Ildemaro, p. 452.

${ }^{91}$ Per questi aspetti si rimanda a C.D. FONSECA, Dal “capitolo" all'“aula capitolare" e R. CERONE, «Regula in capitulo pronunciata fuerit». La sala capitolare nei monasteri medievali (secc. IX-XIII), in Gli spazi della vita comunitaria, Atti del convegno internazionale di studio (Roma-Subiaco, 8-10 giugno 2015), a cura L. Ermini Pani, Spoleto 2016 (De re monastica, V. Incontri di studio, 13), pp. 37-50 e 51-83.

${ }_{92}^{2}$ Ildemaro, pp. 457-46o.

${ }_{93}$ Quando nella Regola si dice «separatus solus», osserva Ildemaro, non si deve intendere nel senso che questi mangi da solo dopo gli altri, ma piuttosto che «quando gli altri mangiano, egli mangi separato e non beva vino. Nel mio monastero in Francia, infatti, ho visto mangiare quel fratello negligente per conto suo in mezzo al refettorio mentre pranzavano anche gli altri» (Ildemaro, pp. 462, 497; RB 43,15; 51,3). Per questi aspetti si rimanda ad G. ARCHETTI, "De mensura potus", pp. 243-244; IDEM, «Infundit vinum et oleum». Olio e vino nella tradizione monastica, in Olio e vino nell'alto medioevo, Spoleto 2007 (Settimane di studio della Fondazione Centro italiano di studi sull'alto medioevo, LIV), pp. 1099-1209.

${ }_{94}$ Per il commento a RB 41: In quali ore bisogna prendere i pasti?, cfr. Ildemaro, pp. 448-452. Sul tema del cibo e dell'alimentazione monastica, con particolare riferimento a RB 39 (La quantità del cibo) e 40 (La quantità del bere) si rimanda ai contributi di chi scrive: "De mensura potus", pp. 205-326; «Infundit vinum et oleum", pp. 1099-1209; Il vino nell'Europa medievale tra storia e storiografia, in Prosit. Excursus storico-archeologico su produzione e uso del vino in Aquileia e in Friuli Venezia Giulia tra Antichità e Medioevo, a cura di S. Blason Scarel, Manzano-Aquileia 2005, pp. 152-167; "Solum in pane et aqua abstinere". L'alimentazione a Fonte Avellana al tempo di Pier Damiani, in Fonte Avellana nel secolo di Pier Damiani, Atti del XXIX Convegno del Centro Studi Avellaniti (Fonte Avellana, 29-31 agosto 2007), a cura di N. D’Acunto, San Pietro in Cariano (Vr) 2008, pp. 179-211; "Vas optimo lacte plenum". Latte e formaggio nel mondo monastico, in La civiltà del latte. Fonti, simboli e prodotti dal Tardoantico al Novecento, Atti dell'incontro nazionale di studio (Brescia, 29-30 maggio 2008), a cura di G. Archetti, A. Baronio, Brescia 2011 (Storia cultura e società, 3), pp. 249-278; "Parvula poma sumebat". Suggestioni dal mondo monastico, in Le parole della frutta. Storia, saperi, immagini tra medioevo ed età contemporanea, a cura di I. Naso, Torino 2012 (Centro studi per la storia dell'alimentazione e della cultura materiale "Anna Maria Nada Patrone"), pp. 67-89; "Vineam noviter pastinare". Note storiche sulla vite e sul vino nella Liguria medievale, in 


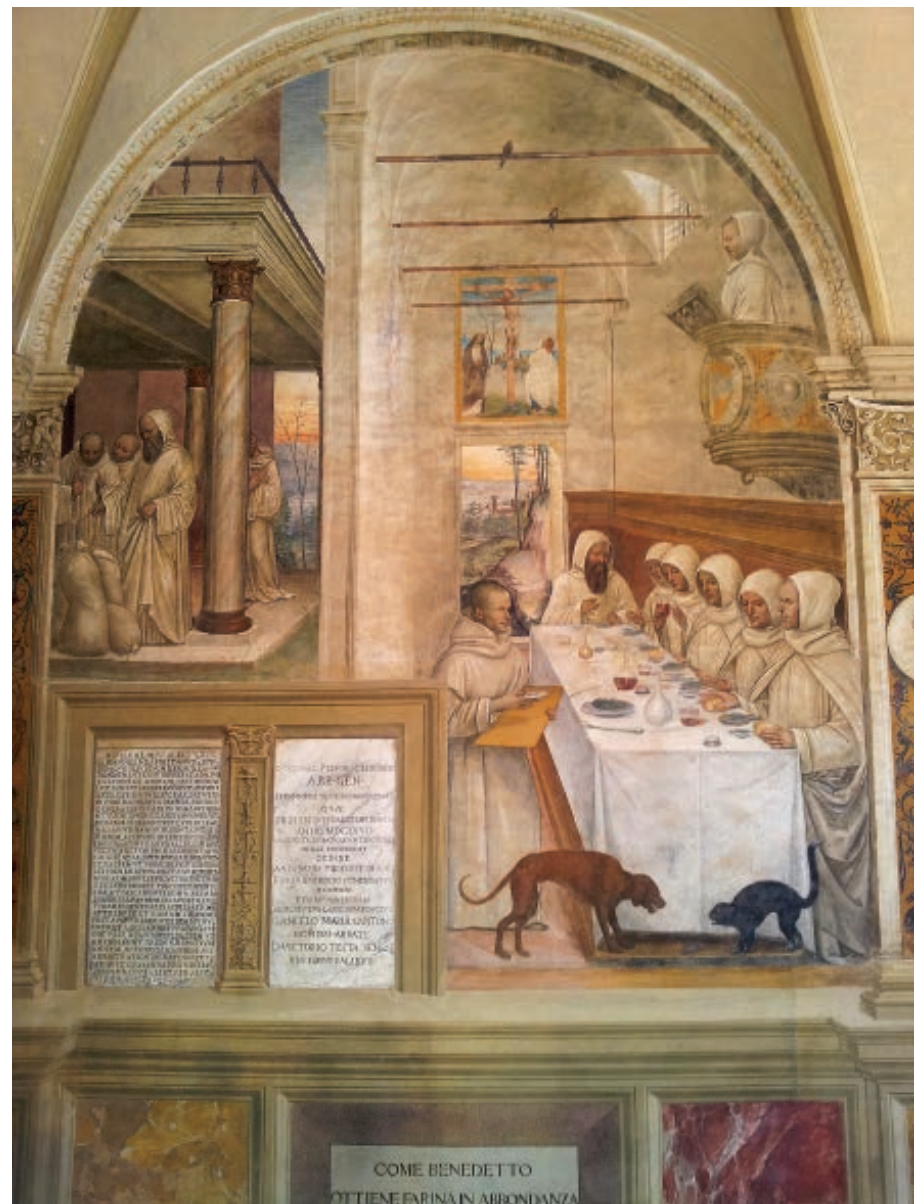

Fig. 21. Abbazia di Monte Oliveto Maggiore, chiostro, lato nord, storie di Benedetto affrescate da Sodoma, Benedetto a pranzo con i monaci nel refettorio, inizio XVI secolo

rituale: dopo essersi lavate le mani, tutti entravano in refettorio, dove i posti erano rigorosamente assegnati seguendo l'anzianità di ingresso nel monastero; i fratelli vi accedevano processionalmente stando in piedi fino all'arrivo dell'abate, che dava la benedizione col segno di croce. Il cibo era distribuito e consumato in silenzio, mentre il lettore dall'alto del pulpito faceva risuonare la sua voce in tutto il refettorio leggendo le Scritture, in modo che al nutrimento del corpo si accompagnasse quello dell'anima. Il tutto, comunque, doveva avvenire «con la luce del giorno» secondo il dettato della Regola (RB 41,9)95.

Nel corso della giornata, sia pure in modo moderato e non chiassoso, vi erano dei momenti in cui era permessa la conversazione nei chiostri: dopo il capitolo del mattino e dopo la cena del tardo pomeriggio, mentre in chiesa, in refettorio e nel dormitorio - come pure in modo assoluto di notte - il silenzio era osservato costantemente e poteva essere infranto solo dal canto comunitario dei salmi e delle letture (RB 6; 7,56-57;38,5; 42,8-9; 52,2). Alla fine del giorno, recitata Compieta, ogni monaco si recava a dormire nel proprio letto nel dormitorio, dove la lampada rimaneva sempre accesa fino al mattino e un fratello vigilava su di loro (RB 22; RM 11,109-121; 29,2-6). I monaci si coricavano vestiti "per essere sempre pronti a levarsi senza indugio al segnale e affrettarsi all'ufficio divino» ( $R B$ 22,6); se qualcuno però faceva fatica ad alzarsi, chi era più scrupoloso lo esortava a destarsi ( $R B$ 22,6-8), mentre uno o due monaci anziani - osserva Ildemaro - andavano con la lanterna accesa per il dormitorio a svegliare i fratelli sonnolenti e senza toccarli, «ma semplicemente battendo contro l'asse del letto o facendo qualcosa del genere, li chiamavano $»{ }^{96}$.

Si tratta di piccole annotazioni sul testo benedettino che mostrano lo sviluppo del monachesimo in età carolingia e di come i suoi sviluppi, dovuti soprattutto ai carichi liturgici codificati poi da Cluny, siano la conseguenza del graduale processo di clericalizzazione dei monaci, in atto già nell'VIII secolo ${ }^{97}$. Rispetto agli asceti del deserto - spesso lontani e svincolati dalla contingenza del loro tempo, per i quali contava veramente il cammino personale della perfezione individuale -, la scelta cenobitica di «piacere solo a Dio» ${ }^{98}$ muoveva dal riconoscimento della funzione centrale della vita comunitaria e dall'esercizio evangelico della carità vicendevole.

\section{IN CAMMINO VERSO LA VITA ETERNA}

All'interno del claustrum nulla era frutto di improvvisazione, ma tutto veniva disciplinato con cura per scongiurare $i$ pericoli dell'otiositas ( $\mathrm{RM}$ 50,2; RB 48,1): insieme si pregava, si lavorava, si leggeva, si mangiava e si dormiva. Per questo il tempo dei monaci è soprattutto un'esperienza comunitaria, dove la condivisione degli spazi e la contiguità delle attività quotidiane del vivere sono la condizione normale. In esso non erano previsti luoghi riservati o privati, perché ogni cosa si svolgeva sotto l'occhio vigile dei fratelli, dei maestri, dei superiori e dell'abate. Quanti intendevano intraprendere la via del chiostro, giunti alla porta del cenobio non erano subito accolti, ma venivano messi in attesa per un lungo periodo, durante il quale dovevano disfarsi dei loro beni, ascoltare la lettura della Regola, imparandola a memoria, e sperimentare la vita monastica sotto la guida di un maestro

"In terra vineata". La vite e il vino in Liguria e nelle Alpi Marittime dal Medioevo ai nostri giorni, Atti del convegno di studi in memoria di Giovanni Rebora (Taggia, 6-8 maggio 2012), a cura di A. Carassale e L. Lo Basso, Ventimiglia (Im) 2014, pp. 13-35; "Noli pane satiari". Il pane sulla mensa dei monaci, in La civiltà del pane. Storia, tecniche e simboli dal Mediterraneo all'Atlantico, Atti del Convegno internazionale di studio (Brescia, 1-6 dicembre 2014), a cura di G. Archetti, Spoleto 2015 (Centro studi longobardi. Ricerche, 1), pp. 1663-1704; "Il vino non è per i monaci". Appunti sparsi sugli usi monastici antichi, in "Dulcius nil est mihi veritate". Studi in onore di Pasquale Corsi, a cura di F. Monteleone e L. Lofoco, Foggia 2015, pp. 65-87; "Mensura victus constituere", pp. 757-797; I monaci a tavola: norme e consuetudini alimentari, in Gli spazi della vita comunitaria, pp. 305-327; "Dulcissimas ficus comedere". Note sparse dalle fonti monastiche, in Fichi. Storia, economia, tradizioni. Figs, History, Economy, Traditions, Atti del convegno internazionale di studio (Sanremo-Bordighera, 22-23 maggio 2015), a cura di A. Carassale, C. Littardi, I. Naso, Ventimiglia (Im) 2016 (Centro studi CeSa. Saggi e ricerche, 1), pp. 105 -118.

${ }^{95}$ L'ora dei pasti è calcolata cioè in funzione della durata della luce diurna, sia per motivi spirituali, sia soprattutto per ragioni di risparmio economico del prezioso combustibile, cfr. La Règle de saint Benoît, VI, p. 1172; e il commento in ARCHETTI, «Infundit vinum et oleum», pp. 1108-1109.

${ }^{96}$ Ildemaro, pp. 335-336; anche G. ARCHETTI, Ildemaro a Brescia e la pedagogia monastica nel commento alla Regola, in San Faustino Maggiore di Brescia: il monastero della città, Atti della giornata nazionale di studio (Brescia, Università Cattolica del Sacro Cuore, 11 febbraio 2005), a cura di G. Archetti, A. Baronio, Brescia 2006 (Brixia sacra. Memorie storiche della diocesi di Brescia, XI, 1), pp. 113-178.

${ }_{97}^{7} \mathrm{~J}$. LECLERCQ, Pour une histoire de la vie à Cluny, in Révue d'histoire ecclésiatique, LVII, 2-3 (1962), pp. 385-408, 783-812.

${ }_{98}^{8}$ GREGORIO MAGNO, Storie di santi e di diavoli (Dialoghi), Introduzione e commento a cura di S. Pricoco, Testo critico e traduzione a cura di M. Simonetti, I, Milano 2005, lib. II: De vita et miraculis venerabilis Benedicti abbatis, Prologo 1, 1, p. 104. 


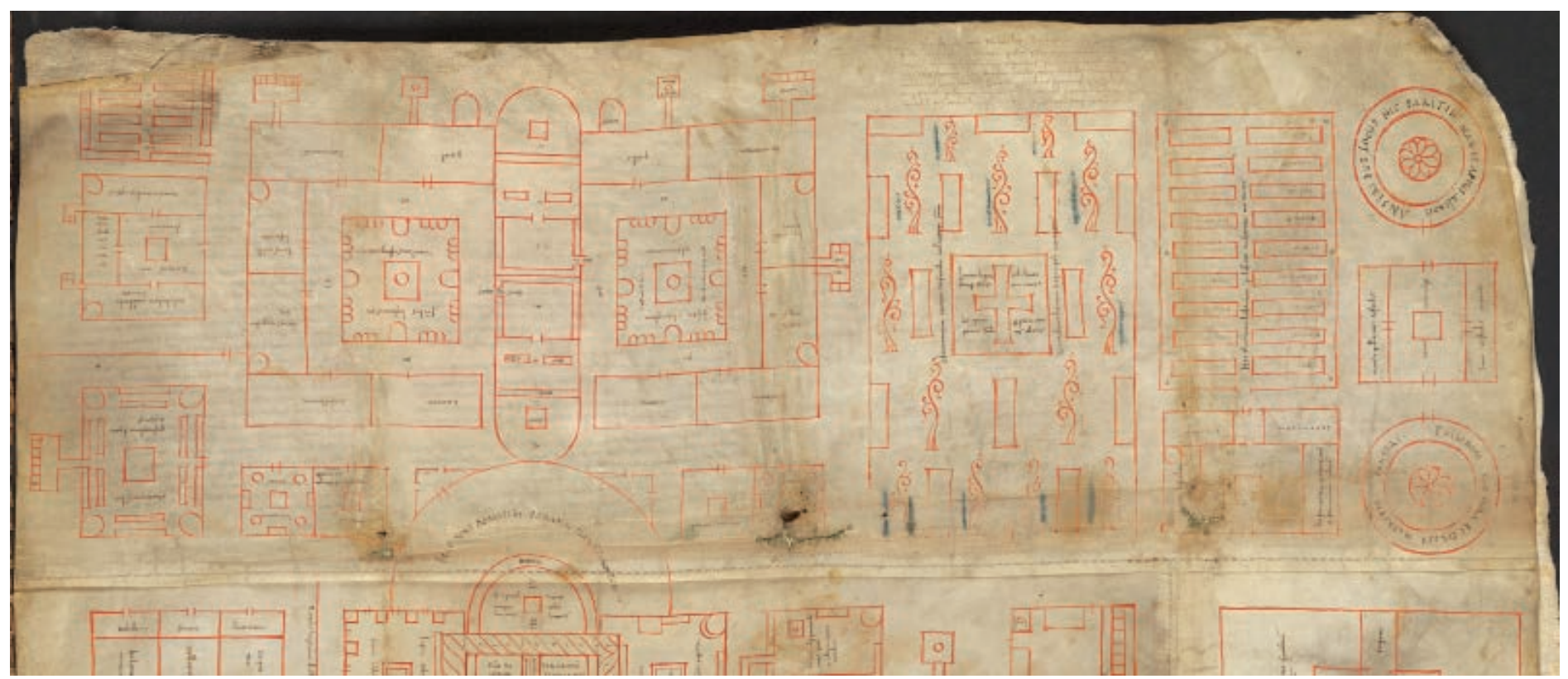

Fig. 22. San Gallo, Stiftsbibliothek, ms 1092, pianta del monastero di San Gallo, particolare dell'area cimiteriale, 816-837

spirituale, che ne saggiava la rettitudine delle intenzioni (RM 87-90; RB 58). Al termine di questo apprendistato, severo e rigoroso, l'aspirante pronunciava la sua promessa di «stabilità, conversione di vita e obbedienza» davanti ai confratelli (RB 58,17). Il suo impegno di vita veniva assunto nell'oratorio con una solenne cerimonia nella quale esprimeva la volontà di «servire Dio nel cenobio», secondo le norme che vi aveva imparato.

È quanto fece a metà dell'XI secolo domina Ermelinda che, indossato il velo monastico, emise la promessa di stabilità, di conversione dei costumi e di obbedienza verso Dio e i suoi santi, come pure fece la sua consorella Ermentruda che, in ginocchio davanti all'altare di San Salvatore e alla badessa Alda, proferì la medesima promessa di stabilità e obbedienza secondo la Regola di san Benedetto nel monastero «costruito in onore di santa Giulia vergine» nella città di Brescia ${ }^{99}$. In quell'occasione il vescovo aveva benedetto le loro vesti di fustanea nigra ed esse le avevano indossate prendendole direttamente dalle sue mani; poi avevano inchinato il capo per ricevere il velo consacrato, con l'impegno di «portarlo senza macchia davanti al tribunale del Signore»; al termine del rito avevano congiunto le loro mani in quelle della superiora in segno di obbedienza e sottomissione ${ }^{100}$.

Era iniziato così il cammino verso la perfezione religiosa di queste sorelle - ma lo stesso avveniva per i monaci -, per le quali la Regola costituiva «soltanto il semplice inizio» del percorso, perseverando nel quale avrebbero raggiunto le alte vette della sapienza e della virtù nell'ascesi cristiana (RB 73,2.8-9). Giunte al termine dei loro giorni, avrebbero continuato ad essere accompagnate dalle consorelle anche nel supremo momento del distacco dalla vita, passaggio doloroso e terribile che - allora come ora - non sempre veniva affrontato con umana rassegnazione. La campana dava il segnale del decesso, le monache si riunivano per pregare, il corpo veniva spogliato e lavato, deposto su un letto di cenere e preparato per la veglia prima della sepoltura nella nuda terra del cimitero (fig. 22), dove il ricordo era affidato ad una croce di legno piantata nel terreno. Una ritualità che nel corso del tempo si era arricchita modificando gli spazi destinati alla liturgia funeraria e le stesse strutture monastiche, come nel caso di Cluny, con l'approntamento della cosiddetta "Galilea". L'esemplarità della vita claustrale però, in taluni casi, era fissata per restare più a lungo nella memoria comunitaria, come accadde nel cenobio giuliano a suor Elena ricordata da un'encomiabile iscrizione funebre nel liber vitae in cui viene paragonata ad un astro «del cielo splendente come le stelle più lucenti $»^{101}$.

Non meno intenso è il racconto agiografico, carico di simboli spirituali e ascetici, della morte del grande abate di Cluny, Ugo di Semur, fatta dal monaco Egidio. «Verso sera [il corpo del venerando padre] fu portato nella chiesa di Santa Maria - cioè nell'infermeria, scrive il suo biografo

\footnotetext{
99 Der Memorial- und Liturgiecodex von San Salvatore / Santa Giulia in Brescia, in MGH, Libri memoriales et necrologia, Nova series, IV, herausgegeben von D. Geuenich und U. Ludwig, unter Mitwirkung von A. Angenendt, G. Muschiol, K. Schmid (†) und J. Vezin, Hannover 200o, p. 194; inoltre, sulla vita interna di questo cenobio femminile, G. ARCHETTI, Per la storia di S. Giulia nel Medioevo. Note storiche in margine ad alcune pubblicazioni recenti, in Brixia sacra. Memorie storiche della diocesi di Brescia, terza serie, V, 1-2 (2000), pp. 5-44; IDEM, Vita e ambienti del monastero dopo il Mille, in San Salvatore - Santa Giulia di Brescia. Il monastero nella storia, a cura di R. Stradiotti, Milano 2001, pp. 109-131; IDEM, "Secundum monasticam disciplinam". San Salvatore di Brescia e le trasformazioni istituzionali di un monastero regio, in Desiderio. Il progetto politico dell'ultimo re longobardo, Atti del Primo convegno internazionale di studio (Brescia, 21-24 marzo 2013), a cura di G. Archetti, Spoleto 2015 (Centro studi longobardi. Convegni, 1), pp. 631-680; F. STROPPA, L'immagine della martire Giulia nel complesso monastico di San Salvatore di Brescia: mobilità di maestranze, di materiali e di idee, HAM, 22 (2016), pp. 265-281; EADEM, Desiderio. La basilica di San Salvatore, Atti del Primo convengo internazionale (Brescia 21-24 marzo 2013), a cura di G. Archetti, Spoleto 2016 (Centro studi longobardi. Convegni 1.2).

${ }^{100}$ Der Memorial, pp. 199-201. L'aspirante alla vita monastica pronunciava la sua promessa di «stabilità, conversione di vita e obbedienza» in modo solenne davanti alla comunità e al superiore (RB 58,17); ciò avveniva nell'oratorio del monastero, dove esprimeva la volontà di «servire Dio nel cenobio» secondo le norme che vi aveva imparato; poi recitava il versetto del salmo: Accoglimi, Signore, secondo la tua parola, e avrò vita; non deludermi nella mia speranza (Sal 118,116), che veniva ripetuto per tre volte dal resto della comunità, aggiungendovi il Gloria Patri, che lo accoglieva al suo interno impegnandosi a pregare per lui» (RB 58,21-23).
}

${ }^{101}$ Der Memorial, p. 194. 
-, che come fu porta di salvezza per i prigionieri e gli esuli, così ora è per chi ad essa ricorre e diventa porta del cielo. Proprio nell'ora in cui i confratelli si pongono a letto, l'abate fu tolto dal suo per essere steso a terra, in segno di umiltà, su un ruvido panno e sulla cenere». Esalato l'ultimo respiro, Ugo fu «portato nella sala capitolare, dove alcuni confratelli, in abiti bianchi lo lavarono prima con l'acqua e poi col vino; da ultimo, con un po' di unguento che era rimasto in un vasetto, vennero unte la testa ed una parte delle altre membra di quel santissimo corpo $»^{102}$. Gesti di religiosa pietà che ricordavano quelli evangelici, fatti perché a tutti i fratelli rimanesse impressa l'immagine del padre, ma soprattutto il suo esempio di vita.

Ma solo pochi giorni prima di quello stesso anno, nel regno dei normanni oltre la Manica, all'alba del mercoledì 21 aprile 1109 vigilia del Giovedì santo, si era spento a Canterbury un altro grande abate, Anselmo, primate della chiesa inglese. Anche il suo corpo «fu lavato secondo l'uso tradizionale» e poi spalmato con un po' di unguento come il corpo del Signore nella speranza «che a quel modo lo si preservasse un po' dalla corruzione»; nel giorno però in cui lo si portava alla sepoltura, racconta il biografo Eadmero, «si scoprì che il sarcofago preparato molti giorni prima gli andava bene in lunghezza» ma non era abbastanza profondo. Si può immaginare l'imbarazzo e il trambusto del momento, quando un giovane monaco animato da spirito di fede, afferrato con le mani il pastorale del vescovo di Rocester che presenziava alle esequie, «iniziò a farlo scorrere in senso trasversale sopra il cadavere e grande fu la nostra sorpresa nel vedere che il corpo del defunto non fuoriusciva più $»^{103}$.

Vivere e morire in monastero ha rappresentato nel corso dei secoli un modo di intendere il tempo e lo spazio della sto- ria intrisi di sacralità e protesi verso l'eterno. Un'esperienza soprattutto comunitaria - anche nel caso degli eremiti la cui vicenda personale, pur nella solitudine più profonda, restava in comunione col resto della Chiesa -, dove la condivisione degli spazi e la contiguità delle attività quotidiane erano la condizione comune. È questo un elemento che unisce i monaci al resto della società medievale ${ }^{104}$, rendendoceli meno estranei nel loro studiato isolamento, mentre il concetto di privacy tanto sbandierato quanto disatteso nel mondo odierno, è frutto di un contesto sociale più ricco e di una coscienza affermatisi nel tardo medioevo, ma estranei al monachesimo altomedievale.

Quanti infatti intendevano intraprendere la via del chiostro, giunti alla porta del monastero non erano accolti subito, ma venivano messi in attesa perché una volta varcata quella soglia e dopo un severo apprendistato, come si legge nell'Historia monachorum, «nessuno di loro poteva poi uscire $»^{105}$. La stabilità in effetti era il tratto distintivo di tale scelta, giacché «se ad uno è parso bello entrare, sa che non ne uscirà mai più (...); ciò che suscita però stupore è il fatto che coloro che vi son dentro non vi sono trattenuti da una legge inderogabile, ma dalla beatitudine che là entro si gode, e dalla perfezione cui si tende».

Com'era tuttavia la vita all'interno del monastero, se a nessuno era permesso di entrare e uscire liberamente, è la stessa fonte a raccontarlo con le parole del guardiano di quel cenobio: «Due soli uomini hanno la facoltà di entrare e uscire, per portare fuori i frutti del lavoro dei monaci, e per introdurre quando è necessario ciò che là dentro non vi si trova. Tutti gli altri monaci se ne stanno in sacro silenzio, in tutta tranquillità, unicamente intenti alla preghiera, alle attività dello spirito, solamente preoccupati di crescere in santità $»^{106}$.

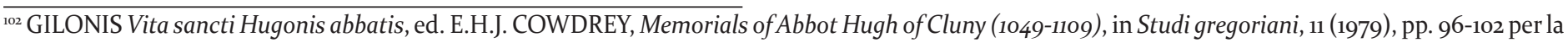
morte; Ugo abate di Cluny. Splendore e crisi della cultura monastica, a cura di G.M. Cantarella, D. Tuniz, Milano 1998, p. 106-107; sul tema cfr. P. HENRIET, Chronique de quelques morts annoncées: les saints abbés clunisiens (Xe-XIe siècles), in Médiévales, 31 (1996), pp. 93-108; come pure D. IOGNA-PRAT, Des morts très spéciaux aux morts ordinaires: la pastorale funéraire clunisienne (XI'-XII ${ }^{e}$ siècles), Ibidem, pp. 79-91; più in generale Moines et moniales devant la mort, Actes du Colloque de Lille (2-4 octobre 1992), Lille 1993 (Histoire médiévale et archéologie, 6).

${ }^{103}$ EADMERO, Vita sancti Anselmi, in Patrologia latina, 158, coll. 116-117; EADMERO DI CANTERBURY, Vita di sant'Anselmo, a cura di S. Gavinelli, Editoriale di I. BIFFI, Milano 1986 (Di fronte e attraverso, 178), pp. 159-160.

${ }^{104}$ Lo conferma Eloisa quando, scrivendo ad Abelardo per farlo recedere dal proposito matrimoniale, gli ricorda che erano solo divites et potentes a possedere case con molte stanze (Historia mearum calamitarum, in The letters of Abelard and Heloise, Harmondsworth 1974, pp. 71-72).

${ }^{105}$ RUFINO, Historia monachorum, col. 439.

${ }^{106}$ RUFINO, Historia monachorum, coll. 439-440.
} 